\title{
Modeling Renewable Energy Systems by a Self-Evolving Nonlinear Consequent Part Recurrent Type-2 Fuzzy System for Power Prediction
}

\author{
Jafar Tavoosi ${ }^{1, *(\mathbb{D})}$, Amir Abolfazl Suratgar ${ }^{2}$, Mohammad Bagher Menhaj ${ }^{2}$, Amir Mosavi ${ }^{3,4, *(D),}$ \\ Ardashir Mohammadzadeh ${ }^{5}$ (D) and Ehsan Ranjbar ${ }^{2}$
}

\section{check for}

updates

Citation: Tavoosi, J.; Suratgar, A.A.; Menhaj, M.B.; Mosavi, A.;

Mohammadzadeh, A.; Ranjbar, E.

Modeling Renewable Energy Systems

by a Self-Evolving Nonlinear

Consequent Part Recurrent Type-2

Fuzzy System for Power Prediction.

Sustainability 2021, 13, 3301. https://

doi.org/10.3390/su13063301

Academic Editor:

Mehdi Seyedmahmoudian

Received: 1 February 2021

Accepted: 7 March 2021

Published: 17 March 2021

Publisher's Note: MDPI stays neutral with regard to jurisdictional claims in published maps and institutional affiliations.

Copyright: (c) 2021 by the authors. Licensee MDPI, Basel, Switzerland. This article is an open access article distributed under the terms and conditions of the Creative Commons Attribution (CC BY) license (https:// creativecommons.org/licenses/by/ $4.0 /)$.
1 Department of Electrical Engineering, Faculty of Engineering, Ilam University, Ilam, Iran

2 Center of Excellence on Control and Robotics, Department of Electrical Engineering, Amirkabir University of Technology, $424 \mathrm{Hafez}$ Ave, Tehran, Iran; a-suratgar@aut.ac.ir (A.A.S.); menhaj@aut.ac.ir (M.B.M.); en.ranjbar.eeng@gmail.com (E.R.)

3 Faculty of Civil Engineering, Technische Universität Dresden, 01069 Dresden, Germany

4 John von Neumann Faculty of Informatics, Obuda University, 1034 Budapest, Hungary

5 Department of Electrical Engineering, University of Bonab, Bonab 551761167, Iran; a.mzadeh@ubonab.ac.ir

* Correspondence: j.tavoosi@ilam.ac.ir (J.T.); amir.mosavi@mailbox.tu-dresden.de (A.M.)

\begin{abstract}
A novel Nonlinear Consequent Part Recurrent Type-2 Fuzzy System (NCPRT2FS) is presented for the modeling of renewable energy systems. Not only does this paper present a new architecture of the type-2 fuzzy system (T2FS) for identification and behavior prognostication of an experimental solar cell set and a wind turbine, but also, it introduces an exquisite technique to acquire an optimal number of membership functions (MFs) and their corresponding rules. Using nonlinear functions in the "Then" part of fuzzy rules, introducing a new mechanism in structure learning, using an adaptive learning rate and performing convergence analysis of the learning algorithm are the innovations of this paper. Another novel innovation is using optimization techniques (including pruning fuzzy rules, initial adjustment of MFs). Next, a solar photovoltaic cell and a wind turbine are deemed as case studies. The experimental data are exploited and the consequent yields emerge as convincing. The root-mean-square-error (RMSE) is less than 0.006 and the number of fuzzy rules is equal to or less than four rules, which indicates the very good performance of the presented fuzzy neural network. Finally, the obtained model is used for the first time for a geographical area to examine the feasibility of renewable energies.
\end{abstract}

Keywords: self-evolving; nonlinear consequent part; convergence analysis; renewable energy; type-2 fuzzy; artificial intelligence; machine learning; big data; data science; fuzzy logic; energy

\section{Introduction}

Renewable energy is expanding rapidly around the world. There are two main reasons for this: one is the issue of fossil fuel pollution and the other is the high cost of fossil fuels. Therefore, research in this field should be developed and supported. One of the powerful tools in data analysis and inference is computational intelligence. Neural networks share lots of significant benefits such as landmark computation ability, parallel processing and adaptation. The fuzzy systems are able to utilize the expert knowledge entitled "if-then rules" and possess actual parameter concepts. As is well known, mathematical modeling is a substantial preliminary step in many control issues. On the other hand, prediction, simulation and modeling of complicated systems established upon physical and chemical principles appear industrious in such a way that they will not yield consolidated mathematical forms [1]. One may suggest system identification as a solution to cope with this problematic issue. This method puts the mathematical equations at the access point, utilizing input-to-output data analysis to increase the efficiency of dynamic process calculations [2]. Computational intelligence lies among the most efficient methods 
with excellent fulfillment. Many papers have recently been published on fuzzy modeling and identification. Nonlinear system identification, founded on fuzzy and neuro-fuzzy models, was surveyed [3]. Computational intelligence becomes extremely feasible in the area of renewable energy [4]. For design MPPT control [5], solar water heater selection [6], photovoltaic system failure diagnosis [7] and solar power plant location alternatives [8], computational intelligence has been used. Neural networks were also used by Grahovac et al. [9] in order to model and anticipate bio-ethanol generation from the intermediates and byproducts yielded in the beet-to-sugar procedure. The productivity of the neurofuzzy controller in extraction of the maximum yield by flow and energy optimization was demonstrated by Khiareddine et al. [10] in comparison with fuzzy and algorithm controllers. It was asserted that the neuro-fuzzy control system is worthy of being executed in an experimental setup in Tunisia. Ocario et al. [11] testified wind power forecasts in the Portuguese system, exploiting a novel hybrid evolutionary-adaptive methodology. Etemadi et al. [12] predicted the wind power produced by data-driven fuzzy modeling.

Type-2 fuzzy (T2F) logic, which appears more capable and flexible in comparison to type-1, has been investigated for the last ten years. A novel method was suggested for general T2F clustering by Doostparast et al. [13]. Some other applications of T2F sets can be found in textile engineering [14] and aerospace engineering [15]. Fuzzy c-means clustering and high order cognitive map were exerted by Lu in order to model and predict time series by T1FS [16]. T2FS identification has engrossed many researchers [17-23]. Abiyev et al. [17] took advantage of T2F clustering to organize construction of a wavelet TSK-based T2FS. They brought forth an adaptive law to update the parameters of the antecedent part and ultimately, they employed a gradient learning algorithm to bring parameters of the descendant part up to date. T2FSs were applied for elicitation of fuzzy rules and casting derogatory features off [24]. The proposed mechanism took advantage of the self-evolution capability in such a way that identification of the integral structure of the network would become efficient and there would be no requirement for initial start-up of the network structure. The antecedent part and modulation parameters are trained in order to hold parameter learning in the network true, utilizing back-propagation errors. Tuning parameters of the resultant part, the rule-ordered Kalman filter algorithm assists in network sharpness amelioration. The genetic algorithm [25] and PSO [26] are among the learning mechanism of T2F neural networks which have been conversed and scrutinized so far. Research development on T2F systems has brought about their vast usages in various fields such as time-series prediction [27], DC motor control [28], clinical practice guideline encryption [29], pattern recognition [30], robot control [31] and control of nonlinear systems [32,33]. A new smart type of reduction is held forth in [34]. A T2FS is optimized by its type-1 counterpart in [35]. The learning process was held true, merging and extending the type- 1 membership functions. Henceforth, the novel constructed T2FS went under implementation on a programmable chip.

It is worth noting that most of the control engineers and system analyzers consider actual systems represented in nonlinear dynamics; not only do these system outputs momentarily turn dependent upon the input, but also, they appear reliant on the delayed inputs/outputs. This leads to a responsible consideration of both external and internal dynamics as a non-negligible essential remark in system modeling. Delayed inputs/outputs have to be used in external dynamics. Another feedback, denoted as "recurrent neuron", has to be exerted in internal dynamics. Wu et al. [36] presented the solution of recurrent FSs for problematic classification. Not only does this paper contribute to minimization of the cost function utilizing a recurrent fuzzy neural network, but it also proposes maximization of the discriminability of adopting a novel approach. Some modern recurrent fuzzy systems are presented in [37]. This special kind of neural network in the resultant part functions input variables in a nonlinear manner. There have hardly been any studies on recurrent T2F systems so far. Some of them are surveyed in the following. A contributive recurrent interval T2FS is presented in order to identify nonlinear systems in [30]. The novel technique requires initial information about plant order and input numbers as well. 
Furthermore, the convergence issue in the learning algorithm is not taken into consideration and conversed even theoretically. Juang et al. [15] put forth another contributive recurrent T2F neural network to model dynamical systems. There is not any rule pruning, which leads to extremely overlapped fuzzy sets. Soft switching of the nonlinear model is superior to the linear one in order to identify nonlinear systems [1]. Consequently, our suggested technique is established upon the nonlinear resultant part in fuzzy rules. Rarely may one find comprehensive works on nonlinear consequent parts in fuzzy systems; however, some of the studies in this arena are shortly surveyed in the following. A reduction in the number of rules was carried out by Moodi in a fuzzy system using the TSK fuzzy model accompanied by a nonlinear consequent part [38]. The result of a rule is supposed to comprise a linear term and a nonlinear one. In their attempts, the numerous rules decrease and model precision simultaneously shows an increase at the cost of complication abundance in the fuzzy model. The NFNN was constructed applying fuzzy rules which merge nonlinear functions. The linear consequent part requires more rules to achieve the desired precision during the modeling of complicated nonlinear processes. The increasing number of rules represents the increasing number of neurons [39]. Some recent works on T2F neural networks can be seen in many applications such as $2 \mathrm{DOF}$ robot control [40], 3 parallel robots control [41], PMSM control [42], water temperature control [43,44], environmental temperature control [45] and UAV control [46]. Tavoosi and Badamchizadeh [47] proposed a T2S with linear "then part" for dynamic modeling. Their pivotal contribution was rule pruning in such a way that an increase in learning speed would be targeted to attain a reduction in the parameters in both MF parameters and descendant parts. Tavoosi et al. [48,49] have made another contribution to the issue, bringing forth a novel technique for analyzing the stability of one class of T2F systems. Another analysis method for stability was also suggested by Jahangiri et al. [50]. Suratgar and Nikravesh [51] proposed a modern technique of fuzzy linguistic modeling as well as integral stability analysis. In [52], a fuzzy neural network has been used for wind speed forecasting. In [53], a comparison between ANFIS and an autoregressive method for wind speed/power prediction has been performed. In [54], a fuzzy control on the basis of a predictive technique for a governing system has been presented. In [55], a multilayer perceptron is combined with an adaptive fuzzy system to forecast the performance of a wind turbine. Some disadvantages and shortcomings of the works studied above are: lack of convergence proof, long training time (not usable in online applications), high complexity of the model, lack of proper accuracy. On the other hand, so far, no applied research has been conducted to use renewable energies in the Ilam region. Unfortunately, there are no wind turbines in this area, and solar cells have also not been used on a large scale to supply electricity to a neighborhood or even several houses. Due to this issue, the main innovation of this paper is the feasibility study of new energy use in the Ilam region.

Therefore, this paper proposes NCPRT2FS for nonlinear system identification. The nonlinear systems here are the same as solar cells and wind turbines. The objective of identifying the system is to use it to specify the efficiency of the renewable energy system in the Ilam region. The innovations of this article are as follows: (1) Using a nonlinear consequent part in the rules. (2) Introducing a new mechanism in structure learning. (3) Using an adaptive learning rate (different from the other studies in the literature). (4) Convergence analysis of the T2F neural network learning algorithm. Finally, (5) New optimization techniques (including pruning fuzzy rules, initial adjustment of MFs, etc.). The paper is divided into six sections. Section 2 presents a short surveying of T2F logic. Section 3 entails an inspection of the structure of NCPRT2FS. The learning convergence of NCPRT2FS is subsumed relying upon Lyapunov theory in Appendix A. Section 4 presents simulative identification studies, taking into account a solar photovoltaic cell and a wind turbine as the case studies and utilizing their experimental data. 


\section{A Review on T2FSs}

Firstly, Zadeh brought forward type-1 fuzzy logic, and introduced the T2F logic in order to provide solutions to some problems of type- 1 ten years later. He deemed a fuzzy set where its MF was fuzzy and entitled a "type-2 fuzzy set". T2F sets may typically be exploited when the determination of accurate membership function becomes arduous. For instance, some time series predictions lie among problematic cases, which necessitate the usage of T2F sets. Hence, exploiting T2F sets emerges as advantageous in order to describe some system behaviors.

Certain defects with type- 1 fuzzy sets were scrutinized by Castro et al. [56]. Research on T2F systems was limited before the years of 1998. Critical and controversial questions and debate on T2F logic and its usage commenced after publication of a book which contained the solidarity and intersection of T2F sets [57]. Extensive information on T2FS computation, such as defuzzification and type reduction, was suggested by Mendel [58]. A general T2F set, $\widetilde{A}$, may be specified by (1):

$$
\widetilde{A}=\int_{x \in X} \mu_{\widetilde{A}}(x) / x=\frac{\int_{x \in X}\left[\int_{\mu \in J_{x}} \frac{f_{x}(\mu)}{\mu}\right]}{x}
$$

where $\mu_{\widetilde{A}}(x)$ is a secondary MF; $J_{x}$ represents the primary membership of $x \in X$, with $\mu \in J_{x} ; f_{x}(\mu) \in[0,1]$ denotes a secondary membership. The primary and secondary MFs in Gaussian form are illustrated in Figure 1.

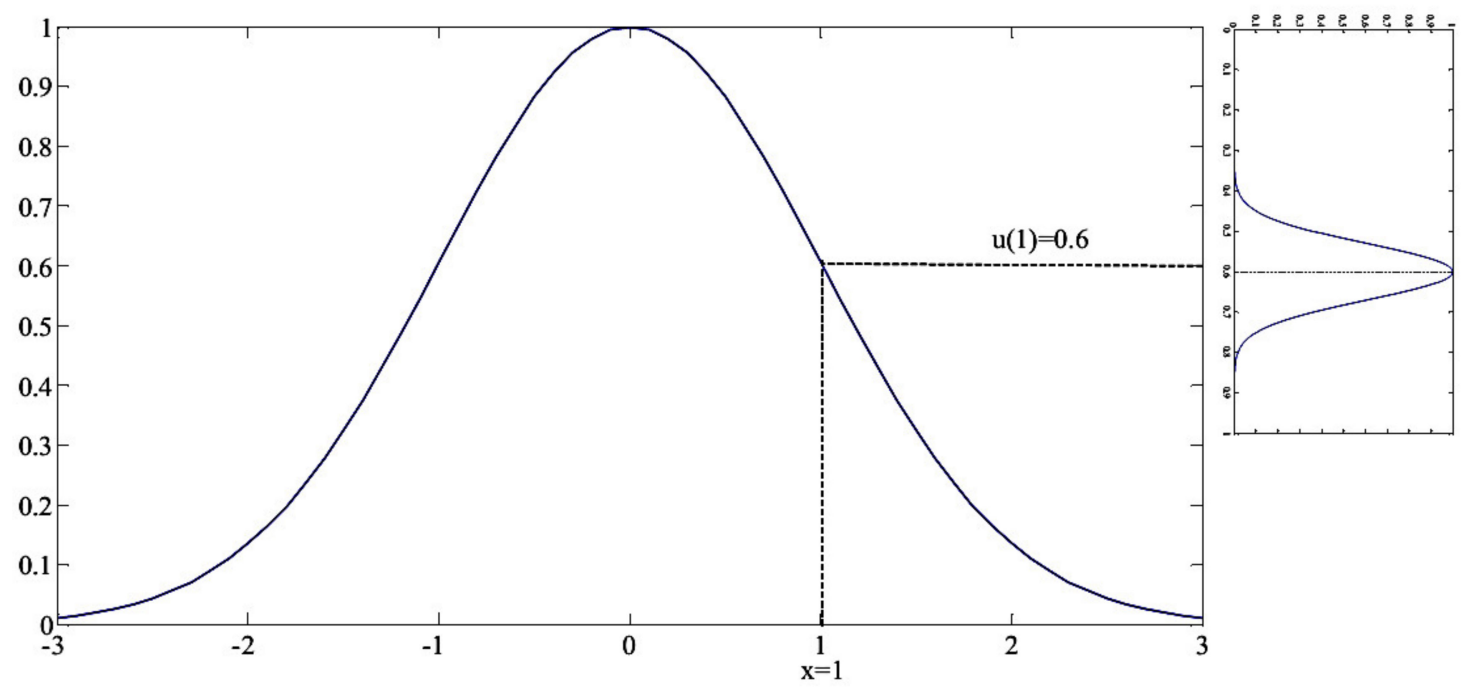

Figure 1. Primary and secondary membership functions (MFs).

Note that the secondary MFs lead to interval T2F ones, while $f_{x}(\mu)=1, \forall \mu \in$ $J_{x} \subseteq[0,1]$. For more explanation, a crisp number would be fuzzified in two stages supposing that Gaussian MF was exerted to attain a T2F number. First,

$$
\mu_{1}=\exp \left(-0.5 \cdot \frac{(x-M)^{2}}{\sigma_{x}^{2}}\right)
$$

where $\mu_{1}$ is the primary membership and $M$ and $\sigma_{x}$ are the primary mean and spread of Gaussian MF, respectively; then,

$$
\mu_{2}\left(x, \mu_{1}\right)=\exp \left(-0.5 \cdot \frac{\left(a-\mu_{1}(x)\right)^{2}}{\sigma_{m}^{2}}\right)
$$


where $\mu_{2}\left(x, \mu_{1}\right)$ is the secondary degree, $a \in[0,1]$ is the domain of the secondary MF for each $x$, and $\sigma_{m}$ is the secondary spread of the Gaussian MF.

Simple and special kinds of general T2F sets change the same as the interval T2F one. Figure 2 depicts two interval T2F sets. A fuzzy set specified by a Gaussian MF by mean/width $m /\left[\sigma_{1}, \sigma_{2}\right]$ is demonstrated in Figure 2a. Two T2F sets are given in Figure 2. Figure $2 b$ illustrates a fuzzy set with an MF of Gaussian form encompassing a distinct standard deviation of $\sigma$. However, the mean value is quite uncertain and adopts values in the interval of $\left[m_{1}, m_{2}\right]$.

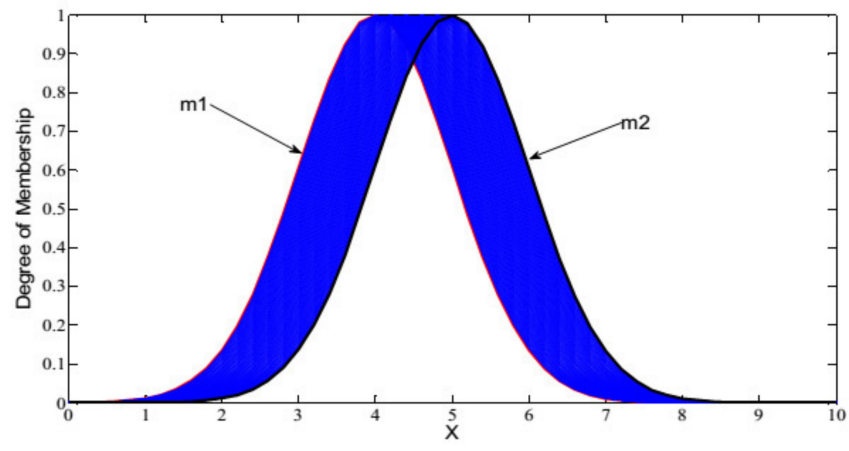

(a)

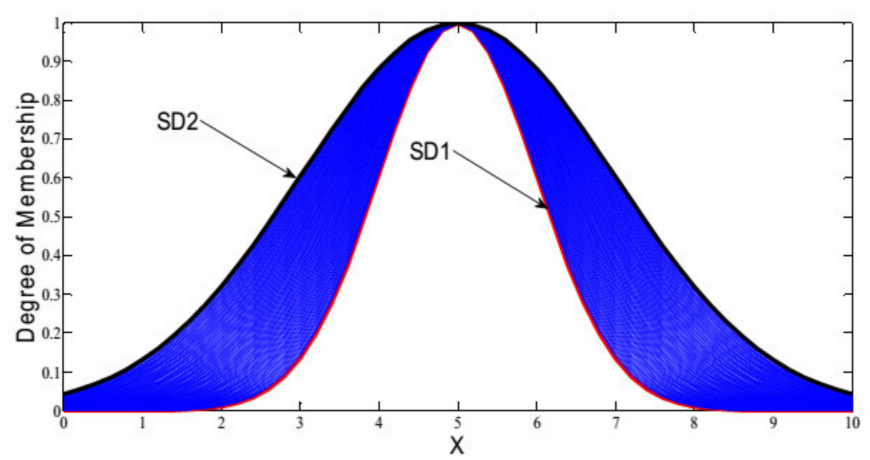

(b)

Figure 2. (a) Uncertainty in width and (b) uncertainty in center.

An MF of Gaussian form with determined $\sigma$ and uncertain $m$, as seen in Figure 2a, is applied through all of this paper.

\section{Type-2 Fuzzy Systems}

One may gain a certain number by defuzzifying a T1FS [59], whereas T2FS yields a T2F set. This is the reason one has to endeavor to succeed in the reduction in fuzzy set type from two to one in a process entitled "Type Reduction". The process is a challenging issue of high significance in T2F systems [60]. Figure 3 displays the structure of a T2F system.

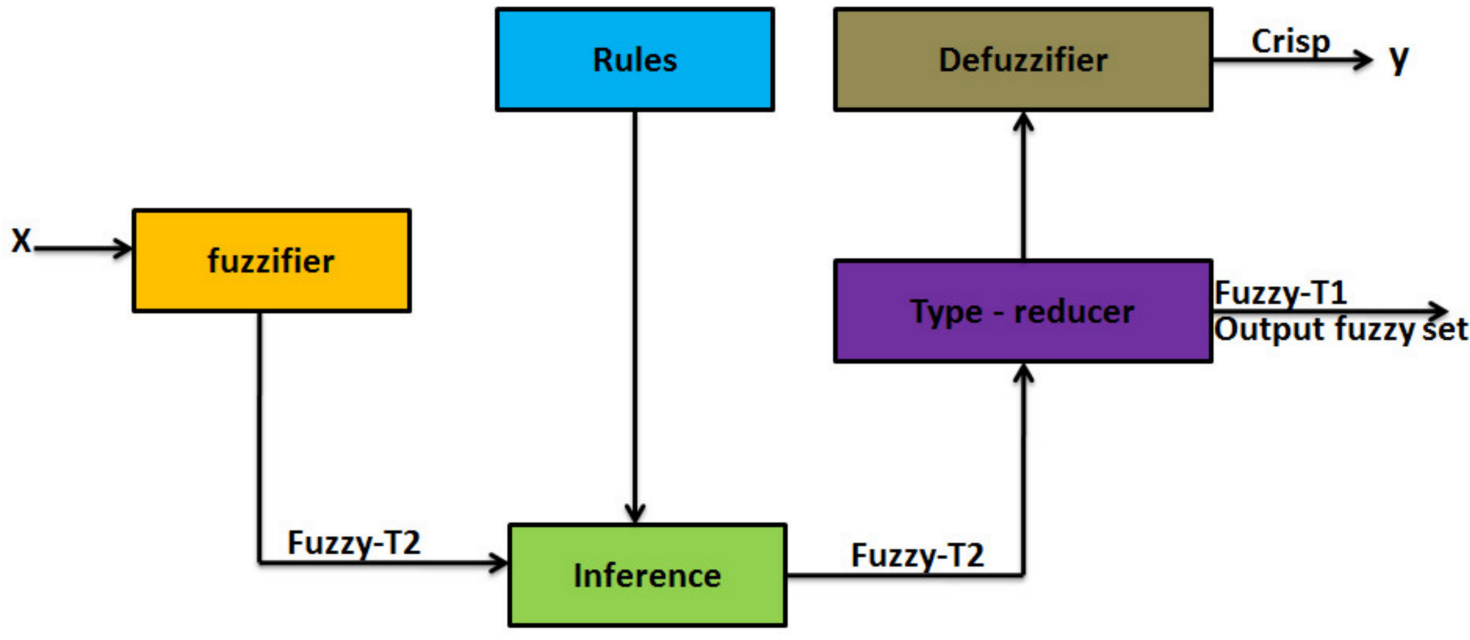

Figure 3. The structure of a T2F system.

As can be easily grasped through Figure 4, construction of the T2FS will be the same as the organization of type-1 if the "Type-Reduction" block is neglected. 


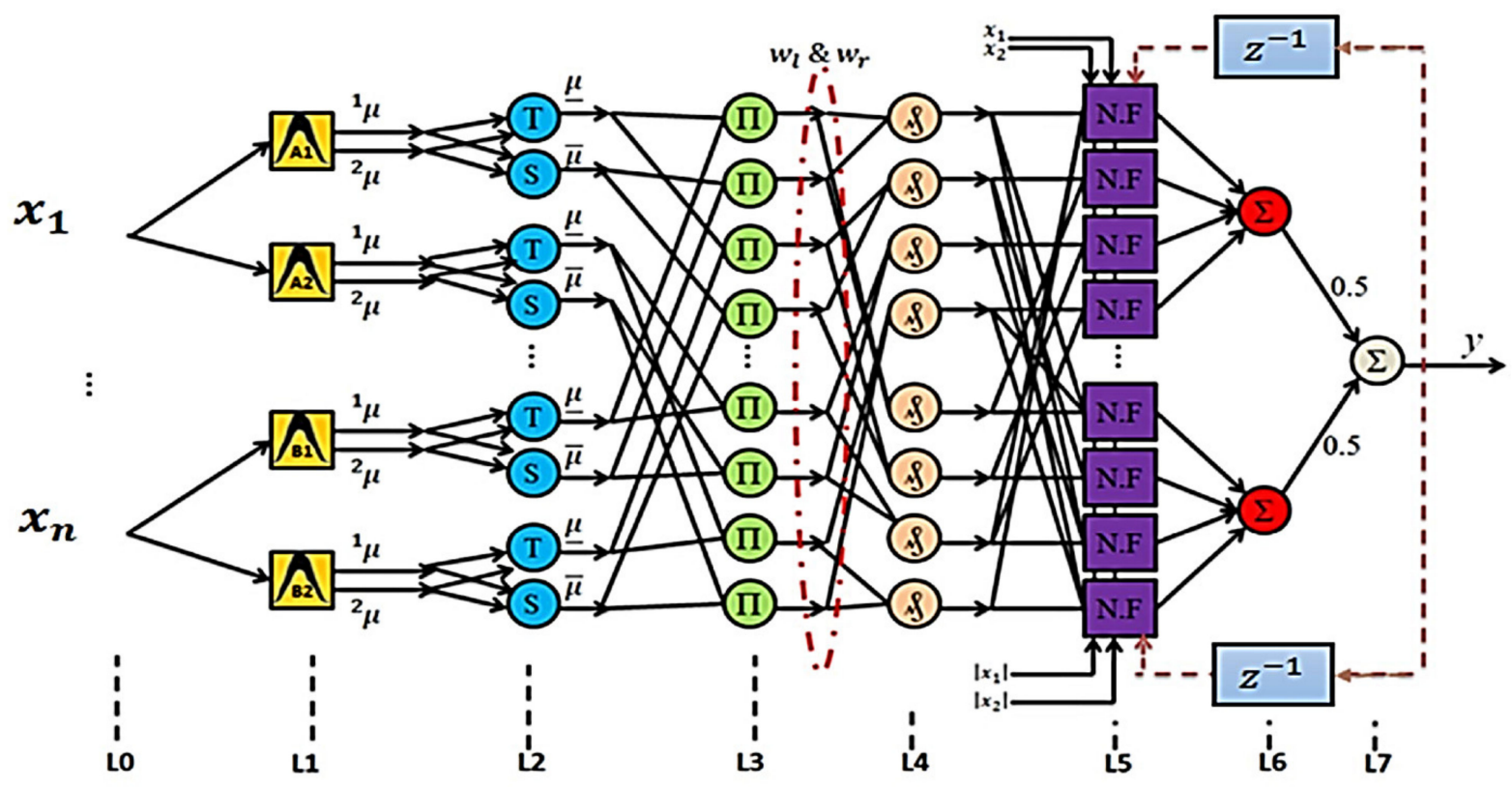

Figure 4. The structure of the proposed NCPRT2FS.

\section{The Proposed NCPRT2FS}

Section 3 tries to consolidate the nonlinear descendant or resultant part of recurrent T2F systems into a formula. Taking into account two informative and useful points that are mentioned later, the descriptive equation of (1) establishes the kth rule:

1) TSK-based T2FSs, usually yield a polynomial constructive of the inputs;

2) The outputs are represented by T1F sets [61].

This study recommends a novel NCPRT2FS, of which its total construction is illustrated in Figure 4. As one may see, the system clearly embodies seven layers. Generally speaking, the kth rule would be demonstrated in the following terms in a first-order T2FS with a TSK model by $M$ rules and $n$ inputs:

$$
R^{k} \text { : if } x_{1} \text { is } \widetilde{A}_{1}^{k} \text { and ... and } x_{n} \text { is } \widetilde{A}_{n}^{k} \text { then } \widetilde{y}_{k}=C_{k, 0}+C_{k, 1} x_{1}+\ldots+C_{k, n} x_{n}
$$

where $k=1, \ldots, M$ is the number of rules, $x_{i}(i=1, \ldots, n)$ are inputs, and $\widetilde{y}_{k}$ is the output of the $k t h$ rule. $\widetilde{y}_{k}$ is an interval T1F set and $\widetilde{A}_{i}^{k}$ are antecedent sets; $C_{k, i} \in\left[c_{k, i}-s_{k, i}, c_{k, i}+s_{k, i}\right]$ represent consequent sets, where $c_{k, i}$ represents the center of $C_{k, i}$ and $s_{k, i}$ is the spread of $C_{k, i}$.

In this paper, the nonlinear consequent part is taken into account. The resulting kth rule in NCPRT2FS, which has two antecedent variables and three outputs with delayed time shift ranging from one unit to three in the descendant part, is demonstrated in (2):

$$
\begin{gathered}
R^{k} \text { : if } x_{1} \text { is } \widetilde{A}_{1}^{k} \text { and } x_{2} \text { is } \widetilde{A}_{2}^{k} \text { then } \\
\widetilde{y}_{k}=C_{k, 0}+C_{k, 1} x_{1}+C_{k, 2} x_{2}+C_{k, 3} y(t-1)+C_{k, 4} x_{1} x_{2}+C_{k, 5} x_{1} y(t-1)+C_{k, 6} x_{2} y(t-1) \\
+C_{k, 7} x_{1}^{2}+C_{k, 8} x_{2}^{2}+C_{k, 9} y^{2}(t-1)+C_{k, 10} x_{1} x_{2} y(t-1)
\end{gathered}
$$

One may make an extension to fuzzy rule (2) considering $n$ antecedent variables and time-delayed outputs in the descendant part with a delaying shift in time ranging from one unit to $\mathrm{m}$ units. $n$ may be designed remarking nonlinearity degree and complexity of the unknown system, which is going to be identified next.

The layers' details are as:

Layer 0: This layer denotes the inputs. 
Layer 1: The outputs of fuzzification are written as:

$$
\begin{aligned}
& { }^{1} \mu_{k, i}\left(x_{i},\left[\sigma_{k, i},{ }^{1} m_{k, i}\right]\right)=e^{-0.5\left(\frac{x_{i}-1 m_{k, i}}{\sigma_{k, i}}\right)^{2}} \\
& { }^{2} \mu_{k, i}\left(x_{i},\left[\sigma_{k, i}{ }^{2} m_{k, i}\right]\right)=e^{-0.5\left(\frac{x_{i}-{ }^{2} m_{k, i}}{\sigma_{k, i}}\right)^{2}}
\end{aligned}
$$

where $m_{k, i} \in\left[{ }^{1} m_{k, i},{ }^{2} m_{k, i}\right]$ and $\sigma_{k, i}$ are the uncertain mean and spread for $k t h$ rule and ith input.

Layer 2: The T-norm and S-norm are computed as:

$$
\begin{gathered}
\underline{\mu}_{k, i}\left(x_{i}\right)={ }^{1} \mu_{k, i}\left(x_{i}\right) \cdot{ }^{2} \mu_{k, i}\left(x_{i}\right), \quad k=1,2, \ldots, M, i=1,2, \ldots, n \\
\bar{\mu}_{k, i}\left(x_{i}\right)={ }^{1} \mu_{k, i}\left(x_{i}\right)+{ }^{2} \mu_{k, i}\left(x_{i}\right)-\underline{\mu}_{k, i}\left(x_{i}\right)
\end{gathered}
$$

Layer 3: The rule firings $\left(\underline{f}^{k}\right.$ and $\left.\bar{f}^{k}\right)$ are:

$$
\underline{f}^{k}=\prod_{i=1}^{n} \underline{\mu}_{k, i} ; \quad \bar{f}^{k}=\prod_{i=1}^{n} \bar{\mu}_{k, i}
$$

Layer 4: The left-most/right-most firing are obtained as:

$$
f_{l}^{k}=\frac{\bar{w}_{l}^{k} \bar{f}^{k}+\underline{w}_{l}^{k} f^{k}}{\bar{w}_{l}^{k}+\underline{w}_{l}^{k}} ; f_{r}^{k}=\frac{\bar{w}_{r}^{k} \bar{f}^{k}+\underline{w}_{r}^{k} \underline{f}^{k}}{\overline{w_{r}^{k}+\underline{w}_{r}^{k}}}
$$

where $w$ are adjustable weights.

Layer 5: The rule left/right firings are:

$$
\begin{aligned}
y_{l}^{k} & =c_{k, 0}+c_{k, 1} x_{1}+c_{k, 2} x_{2}+c_{k, 3} y(t-1)+c_{k, 4} x_{1} x_{2}+c_{k, 5} x_{1} y(t-1) \\
& +c_{k, 6} x_{2} y(t-1)+c_{k, 7} x_{1}^{2}+c_{k, 8} x_{2}^{2}+c_{k, 9} y^{2}(t-1) \\
& +c_{k, 10} x_{1} x_{2} y(t-1)-s_{k, 0}-s_{k, 1}\left|x_{1}\right|-s_{k, 2}\left|x_{2}\right|-s_{k, 3}|y(t-1)| \\
& -s_{k, 4}\left|x_{1} x_{2}\right|-s_{k, 5}\left|x_{1} y(t-1)\right|-s_{k, 6}\left|x_{2} y(t-1)\right|-s_{k, 7} x_{1}^{2} \\
& -s_{k, 8} x_{2}^{2}-s_{k, 9} y^{2}(t-1)-s_{k, 10} x_{1} x_{2} y(t-1) \\
y_{r}^{k} & =c_{k, 0}+c_{k, 1} x_{1}+c_{k, 2} x_{2}+c_{k, 3} y(t-1)+c_{k, 4} x_{1} x_{2}+c_{k, 5} x_{1} y(t-1) \\
& +c_{k, 6} x_{2} y(t-1)+c_{k, 7} x_{1}^{2}+c_{k, 8} x_{2}^{2}+c_{k, 9} y^{2}(t-1) \\
& +c_{k, 10} x_{1} x_{2} y(t-1)+s_{k, 0}+s_{k, 1}\left|x_{1}\right|+s_{k, 2}\left|x_{2}\right|+s_{k, 3}|y(t-1)| \\
& +s_{k, 4}\left|x_{1} x_{2}\right|+s_{k, 5}\left|x_{1} y(t-1)\right|+s_{k, 6}\left|x_{2} y(t-1)\right|+s_{k, 7} x_{1}^{2} \\
& +s_{k, 8} x_{2}^{2}+s_{k, 9} y^{2}(t-1)+s_{k, 10} x_{1} x_{2} y(t-1)
\end{aligned}
$$

Layer 6: $\hat{y}_{l}$ and $\hat{y}_{r}$ are:

$$
\begin{gathered}
\hat{y}_{l}=\frac{\sum_{k=1}^{M} f_{l}^{k} y_{l}^{k}}{\sum_{k=1}^{M} f_{l}^{k}} \\
\hat{y}_{r}=\frac{\sum_{k=1}^{M} f_{r}^{k} y_{r}^{k}}{\sum_{k=1}^{M} f_{r}^{k}}
\end{gathered}
$$

Layer 7: The output is:

$$
\hat{y}=\frac{\hat{y}_{l}+\hat{y}_{r}}{2}
$$

In this article, structure learning is realized by exploiting T2F clustering. As one knows, an efficacious method is suggested to procreate fuzzy rules in real-time and decrease computations in antecedent part in structure optimization [62]. Structure learning appears 
as a great assistance in the simplification of T2FS, taking advantage of the reduction in fuzzy rules. Scrutinizing more, its duty is not only the production of novel membership but also pruning additional MFs and rules. In the input layer, a rule geometrically represents a cluster. Its firing degree could be taken into account as the degree of input data that belongs to a cluster. The center of the firing degree in NCPRT2FS is calculated by (16) since it is an interval.

$$
f_{k}=\frac{f^{k}+\bar{f}^{k}}{2}
$$

Additionally, for generation of a new MF, find:

$$
\mu_{\widetilde{A}_{i}^{k}}=\frac{\underline{\mu}_{\widetilde{A}_{i}^{k}}+\bar{\mu}_{\widetilde{A}_{i}^{k}}}{2}, i=1,2, \ldots, n
$$

For every incoming data $\vec{x}=\left\{x_{1}, \ldots, x_{n}\right\}$, calculate:

$$
I=\arg \max _{1 \leq k \leq M(t)} f_{k}
$$

For newly generated rules:

$$
I_{i}=\arg \max _{1 \leq k \leq k_{i}(t)} \mu_{\widetilde{A}_{i}^{k}}, \quad i=1,2, \ldots, n
$$

where $M(t)$ is the existing number of rules at time $t$. If $I \leq \varnothing_{t h}$, the system generates a new rule, where $\varnothing_{t h} \in(01)$ is a threshold that is defined [63]. If $I_{i}>\rho$, where $\rho \in[01]$ is a previously defined threshold, then use the existing fuzzy set $\widetilde{A}_{i}^{I_{i}}$ as the antecedent part of the new rule in input variable $i$. Otherwise, one could produce a novel MF in input variable $i$ and hold the equation, $k_{i}(t+1)=k_{i}(t)+1$, true. The number of MFs is defined by the parameter $\rho$ in each input variable. Fuzzy clustering is a technique to structure a fuzzy model [64]. A new T2F clustering technique, which is a development of Krishnapuram and Keller Possibilistic C-Mean (PCM) [65], is suggested and described by:

$$
\begin{aligned}
& J_{m}(x, \widetilde{\mu}, c)=\min \left[\sum_{i=1}^{c} \sum_{j=1}^{N} \widetilde{\mu}_{i j}^{m} D_{i j}+\sum_{i=1}^{c} \eta_{i} \sum_{j=1}^{N}\left(1-\widetilde{\mu}_{i j}\right)^{m}\right] \\
& \text { S.T : }\left\{\begin{array}{l}
0<\sum_{j=1}^{N} \widetilde{\mu}_{i j}<N \\
\widetilde{\mu}_{i j} \in[0,1] \quad \forall i, j \\
\max \widetilde{\mu}_{i j}>0 \quad \forall j
\end{array}\right.
\end{aligned}
$$

where $\widetilde{\mu}_{i j}$ is type- $2 \mathrm{MF}$ in the $j^{\text {th }}$ data for the $i^{\text {th }}$ cluster. Moreover, the symbols $D_{i j}, \mathrm{c}$, and $\mathrm{N}$ are the Euclidean distance of the $j^{\text {th }}$ data in the $i^{\text {th }}$ cluster center, clusters and input data numbers, respectively. $\eta_{i}$ is also a positive number. $D_{i j}$ has to be as small as possible as the first term. On the other hand, the memberships in a cluster have to be greater as much as possible. They have to stay in the interval of $[0,1]$ and their sum is confined to become smaller than the number of input data. Equation (21) appears as the descriptive term. That $\eta_{i}$ corresponds to ith cluster, and is of the order of $D_{i j}$, is greatly welcomed [65]. The distance to the cluster's center must be as low as possible (first term). It is desirable that $\eta_{i}$ relate to $i^{t h}$ cluster and be of the order of $D_{i j}$ [63].

$$
\eta_{i}=\frac{\sum_{j=1}^{N} \widetilde{\mu}_{i j}^{m} D_{i j}}{\sum_{j=1}^{N} \widetilde{\mu}_{i j}^{m}} \quad \forall i=1, \ldots, c
$$


Using (20), the optimal values of the centers of the clusters are achieved. The initial $m_{k, i}$ and $\sigma_{k, i}$ for the $k_{i}(t+1)$ th interval T2F set are:

$$
\begin{gathered}
m_{k, i} \in\left[v_{i}-0.1 v_{i}, v_{i}+0.1 v_{i}\right] \\
\sigma_{k_{i}(t+1) i}=\beta\left|v_{i}-\frac{{ }^{1} m_{I_{i}, i}+{ }^{2} m_{I_{i}, i}}{2}\right|
\end{gathered}
$$

where $v_{i}$ is the optimal value of the cluster's center; $\beta>0$ denotes the degree of overlap between 2 fuzzy sets. In this study, $\beta$ is considered to be 0.5 [61]. The parameters of the consequent part are initialized as:

$$
\left[c_{k, 0}-s_{k, 0}, c_{k, 0}+s_{k, 0}\right]=[y d-0.1, y d+0.1], \quad k=1,2, \ldots, M
$$

where $y d$ is the target signal for input $\vec{x}=\left\{x_{1}, \ldots, x_{n}\right\}$. All the other consequent parameters are zero.

By repeating the above process for each training dataset, new rules are created one after the other until NCPRT2FS is finally complete. The network output is calculated for each input applied. The calculated output is then compared to the target to obtain an error. Assume that the input-output data pair $\left\{\left(x_{p}: t_{p}\right)\right\} \forall p=1, \ldots, q$, where $p$ represents the data numbers and $x / t$ is the input/output, respectively. The NCPRT2FS output error can be expressed as follows:

$$
\begin{gathered}
e_{p}=t_{p}-\hat{y}_{p}, \\
E_{p}=\frac{1}{2} e_{p}^{2}=\frac{1}{2}\left(t_{p}-\hat{y}_{p}\right)^{2} \\
E=\sum_{p=1}^{q} E_{p}
\end{gathered}
$$

The gradient-based learning algorithm is used for updating the parameters. The mathematical relation of the gradient-based update algorithm is as follows.

$$
W_{\text {new }}=W_{\text {old }}-\eta \frac{\partial E}{\partial W}
$$

See Appendix A for more details on the parameter update formulation. We choose the initial $\eta$ as:

$$
\eta=\frac{1}{\max \left|\frac{\partial \hat{y}(k)}{\partial W}\right|^{2}}
$$

After all the data have been applied, the variable learning rate is determined by the following form.

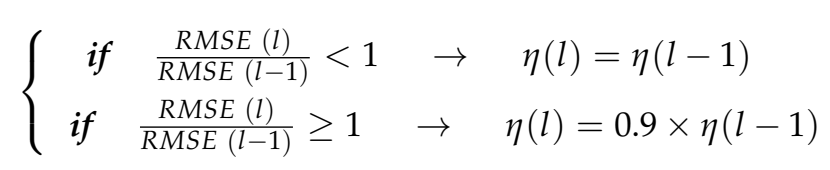

where $l$ is the number of iterations. The RMSE formula is as follows:

$$
R M S E=\sqrt{\frac{1}{N} \sum_{p=1}^{N}\left(t_{p}-\hat{y}_{p}\right)^{2}}
$$

where $t_{p}$ and $\hat{y}_{p}$ are actual and model (NCPRT2FS) outputs at $p$ moment, respectively. The total number of data is denoted by $N$. 


\section{Simulation Results}

Two real renewable energy systems are used for identification. The structure is shown in Figure 5.

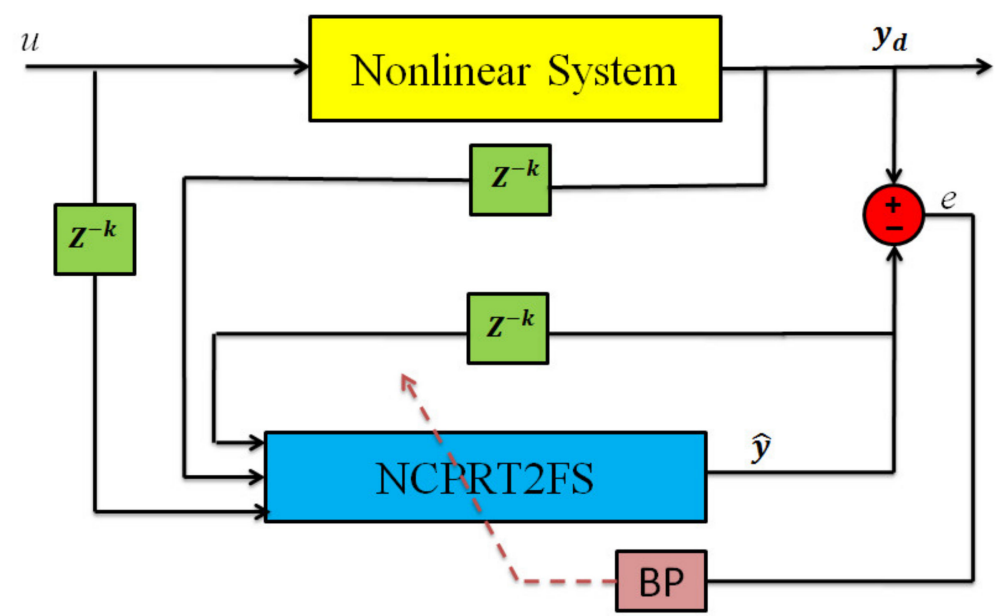

Figure 5. The structure of the system and the NCPRT2FS-based identifier.

The inputs to the NCPRT2FS-based identifier are the main input and delayed system output. The parameters of the NCPRT2FS structure should be adjusted to minimize plant output yd and identification yield $\hat{y}$ for all input values of $x$.

Example 1: Real data of a $660 \mathrm{kw}$ wind turbine (see Figure 6) have been taken from the Iran Renewable Energy Organization (SUNA) (http:/ /www.suna.org.ir/en/home/ 1 March 2021). The model of the wind turbine is $547-660 \mathrm{kw}$, made by VESTAS (Denmark), and information is given in Table 1.

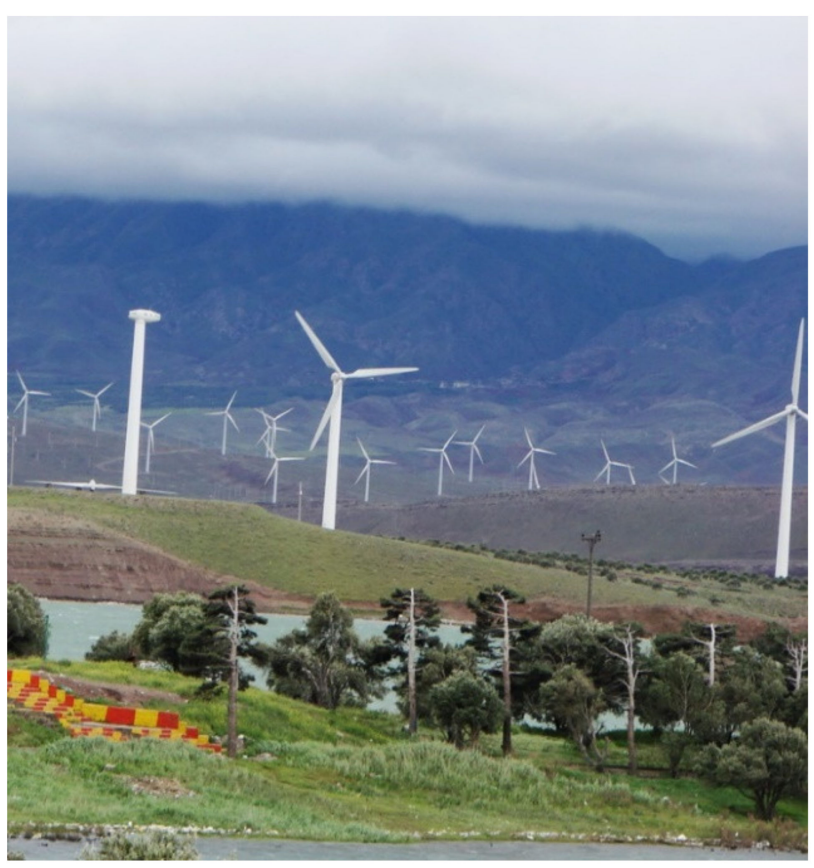

Figure 6. Manjil and Rudbar Wind Farm.

In this example, $u(k), k=1, \ldots, 365$ is wind speed that is fed to the wind turbine system and obtains the 365 samples of $y(k)$, which is the output power of the wind turbine. The other conditions are the same as example 1. Figure 7 exhibits the identification 
performance of the NCPRT2FS. Here, the output (solid line) and the NCPRT2FS identifier output (dashed line) are shown.

Table 1. Information for Example 1.

\begin{tabular}{|c|c|c|c|}
\hline \multicolumn{2}{|c|}{$\begin{array}{l}\text { Cut-in wind speed: } \\
\text { Survival wind speed: } \\
\text { Rated wind speed: } \\
\text { Cut-out wind speed: }\end{array}$} & \multicolumn{2}{|c|}{$\begin{array}{l}4 \mathrm{~m} / \mathrm{s} \\
60 \mathrm{~m} / \mathrm{s} \\
15 \mathrm{~m} / \mathrm{s} \\
25 \mathrm{~m} / \mathrm{s}\end{array}$} \\
\hline \multicolumn{2}{|c|}{ Rotor: } & \multicolumn{2}{|c|}{ Generator: } \\
\hline Number of blades: & 3 & Type: & Asynchronous \\
\hline Swept area: & $1.735 \mathrm{~m}^{2}$ & Number: & 1.0 \\
\hline Type: & 22.90 & Grid connection: & Thyristor \\
\hline Rotor speed, max: & $28.50 \mathrm{U} / \mathrm{min}$ & & \\
\hline Tipspeed: & $70.10 \mathrm{~m} / \mathrm{s}$ & Voltage: & $400 \mathrm{~V}$ \\
\hline Diameter: & $47 \mathrm{~m}$ & Speed, max: & $1.650 \mathrm{U} / \mathrm{min}$ \\
\hline Material: & GFK & Grid frequency: & $50 \mathrm{~Hz}$ \\
\hline
\end{tabular}

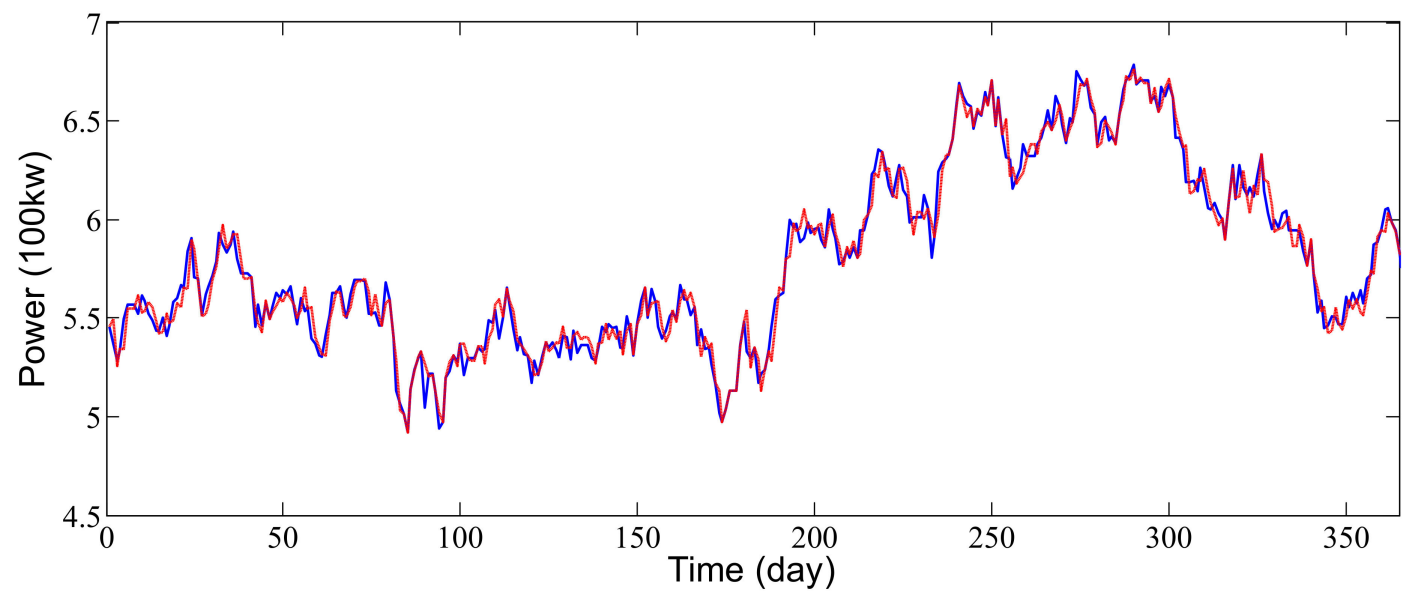

Figure 7. Identification performance of the NCPRT2FS for wind turbine.

The trained NCPRT2FS is used to calculate wind power in a place called Ilam (A city in the west of the Islamic Republic of Iran). Figure 8 shows the wind speed of Ilam for a year. Figure 9 shows the predicted wind power in Ilam.

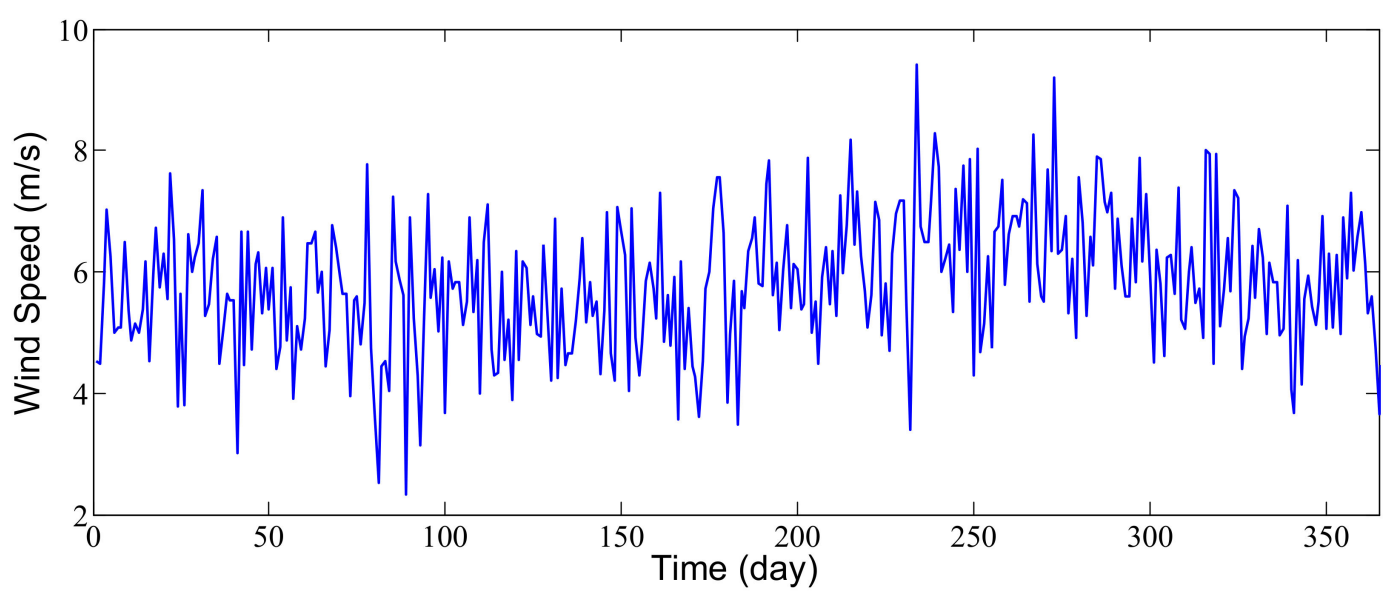

Figure 8. Wind speed of a place in Ilam for a year. 


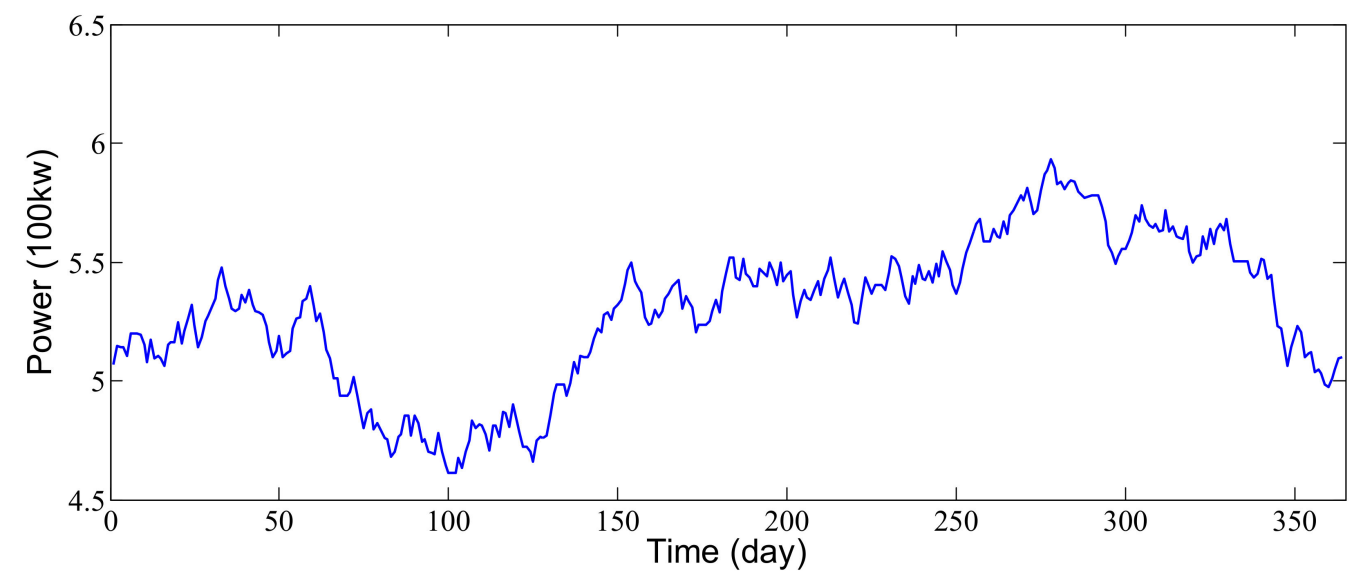

Figure 9. Predicted wind power of a place in Ilam for a year.

The final values of the parameters of NCPRT2FS are shown in Table 2.

Table 2. The final values of NCPRT2FS parameters.

\begin{tabular}{|c|c|c|c|c|c|c|c|c|}
\hline \multirow{3}{*}{$\begin{array}{l}\text { Antecedent } \\
\text { parameters }\end{array}$} & & & \multicolumn{2}{|c|}{${ }^{1} m_{i j}$} & \multicolumn{2}{|c|}{${ }^{2} m_{i j}$} & \multicolumn{2}{|c|}{$\sigma_{i j}$} \\
\hline & \multicolumn{2}{|c|}{$\mathbf{u}(\mathbf{k})$} & \multicolumn{2}{|c|}{$\begin{array}{l}{ }^{1} m_{11}=3.62 \\
{ }^{1} m_{21}=6.13 \\
{ }^{1} m_{31}=8.19\end{array}$} & \multicolumn{2}{|c|}{$\begin{array}{l}{ }^{2} m_{11}=4.32 \\
{ }^{2} m_{21}=7.02 \\
{ }^{2} m_{31}=9.51\end{array}$} & \multicolumn{2}{|c|}{$\begin{array}{l}\sigma_{11}=0.38 \\
\sigma_{21}=1.10 \\
\sigma_{31}=0.89\end{array}$} \\
\hline & \multicolumn{2}{|c|}{$y(k-1)$} & \multicolumn{2}{|c|}{$\begin{array}{l}{ }^{1} m_{12}=4.93 \\
{ }^{1} m_{22}=5.34 \\
{ }^{1} m_{32}=5.81 \\
{ }^{1} m_{42}=6.11\end{array}$} & \multicolumn{2}{|c|}{$\begin{array}{l}{ }^{2} m_{12}=5.12 \\
{ }^{2} m_{22}=5.66 \\
{ }^{2} m_{32}=5.98 \\
{ }^{2} m_{42}=6.48\end{array}$} & \multicolumn{2}{|c|}{$\begin{array}{l}\sigma_{12}=0.21 \\
\sigma_{22}=0.09 \\
\sigma_{32}=0.36 \\
\sigma_{42}=0.18\end{array}$} \\
\hline \multirow{4}{*}{$\begin{array}{c}\text { fourth layer } \\
\text { adaptive } \\
\text { weights }\end{array}$} & \multicolumn{2}{|c|}{$\bar{w}_{r}^{1}=1.92$} & \multicolumn{2}{|c|}{$\underline{w}_{\mathrm{r}}^{1}=1.50$} & \multicolumn{2}{|c|}{$\bar{w}_{l}^{1}=1.00$} & \multicolumn{2}{|c|}{$\underline{w}_{1}^{1}=0.63$} \\
\hline & \multicolumn{2}{|c|}{$\bar{w}_{r}^{2}=1.66$} & \multicolumn{2}{|c|}{$\underline{w}_{\mathrm{r}}^{2}=0.92$} & \multicolumn{2}{|c|}{$\bar{w}_{l}^{2}=0.71$} & \multicolumn{2}{|c|}{$\underline{w}_{1}^{2}=0.06$} \\
\hline & \multicolumn{2}{|c|}{$\bar{w}_{r}^{3}=0.80$} & \multicolumn{2}{|c|}{$\underline{w}_{\mathrm{r}}^{3}=0.70$} & \multicolumn{2}{|c|}{$\bar{w}_{l}^{3}=0.56$} & \multicolumn{2}{|c|}{$\underline{w}_{1}^{3}=0.43$} \\
\hline & \multicolumn{2}{|c|}{$\bar{w}_{r}^{4}=1.87$} & \multicolumn{2}{|c|}{$\underline{w}_{\mathrm{r}}^{4}=0.94$} & \multicolumn{2}{|c|}{$\bar{w}_{l}^{4}=0.85$} & \multicolumn{2}{|c|}{$\underline{w}_{1}^{4}=0.77$} \\
\hline \multirow{12}{*}{$\begin{array}{l}\text { consequent } \\
\text { parameters }\end{array}$} & Rule 1 & Rule 2 & Rule 3 & Rule 4 & Rule 1 & Rule 2 & Rule 3 & Rule 4 \\
\hline & $s_{1,0}=0.40$ & $s_{2,0}=0.33$ & $s_{3,0}=0.27$ & $s_{4,0}=0.52$ & $c_{1,0}=1.00$ & $c_{2,0}=1.40$ & $c_{3,0}=1.00$ & $c_{4,0}=1.40$ \\
\hline & $s_{1,1}=0.55$ & $s_{2,1}=0.39$ & $s_{3,1}=0.48$ & $s_{4,1}=0.43$ & $c_{1,1}=1.10$ & $c_{2,1}=1.00$ & $c_{3,1}=1.00$ & $c_{4,1}=1.00$ \\
\hline & $s_{1,2}=1.00$ & $s_{2,2}=1.00$ & $s_{3,2}=1.00$ & $s_{4,2}=1.00$ & $c_{1,2}=1.00$ & $c_{2,2}=1.32$ & $c_{3,2}=0.81$ & $c_{4,2}=0.93$ \\
\hline & $s_{1,3}=0.43$ & $s_{2,3}=0.39$ & $s_{3,3}=0.65$ & $s_{4,3}=0.90$ & $c_{1,3}=1.00$ & $c_{2,3}=1.00$ & $c_{3,3}=1.65$ & $c_{4,3}=1.82$ \\
\hline & $s_{1,4}=0.62$ & $s_{2,4}=1.00$ & $s_{3,4}=1.00$ & $s_{4,4}=1.00$ & $c_{1,4}=1.00$ & $c_{2,4}=1.09$ & $c_{3,4}=1.00$ & $c_{4,4}=1.00$ \\
\hline & $s_{1,5}=0.87$ & $s_{2,5}=0.10$ & $s_{3,5}=1.00$ & $s_{4,5}=1.00$ & $c_{1,5}=1.10$ & $c_{2,5}=1.00$ & $c_{3,5}=1.55$ & $c_{4,5}=1.90$ \\
\hline & $s_{1,6}=1.00$ & $s_{2,6}=1.00$ & $s_{3,6}=1.00$ & $s_{4,6}=1.00$ & $c_{1,6}=1.00$ & $c_{2,6}=1.00$ & $c_{3,6}=1.00$ & $c_{4,6}=1.00$ \\
\hline & $s_{1,7}=0.69$ & $s_{2,7}=0.66$ & $s_{3,7}=0.31$ & $s_{4,7}=0.06$ & $c_{1,7}=0.80$ & $c_{2,7}=0.72$ & $c_{3,7}=0.67$ & $c_{4,7}=0.81$ \\
\hline & $s_{1,8}=0.96$ & $s_{2,8}=0.11$ & $s_{3,8}=0.54$ & $s_{4,8}=0.21$ & $c_{1,8}=1.10$ & $c_{2,8}=1.00$ & $c_{3,8}=0.92$ & $c_{4,8}=0.59$ \\
\hline & $s_{1,9}=0.30$ & $s_{2,9}=0.32$ & $s_{3,9}=0.36$ & $s_{4,9}=0.98$ & $c_{1,9}=0.95$ & $c_{2,9}=0.77$ & $c_{3,9}=1.00$ & $c_{4,9}=1.00$ \\
\hline & $s_{1,10}=0.35$ & $s_{2,10}=0.31$ & $s_{3,10}=0.54$ & $s_{4,10}=0.50$ & $c_{1,10}=1.00$ & $c_{2,10}=0.44$ & $c_{3,10}=0.64$ & $c_{4,10}=0.89$ \\
\hline
\end{tabular}

Example 2: A real solar cell system is shown in Figure 10.

In this example, $u(k), k=1, \ldots, 600$ is solar radiation that is fed to the real solar cell system and 600 samples of $y(k)$ are obtained. The other conditions are the same as in examples 1 and 2. Figure 11 shows the identification performance of the NCPRT2FS for three solar radiations. Here, the plant output (solid line) and the NCPRT2FS identifier output (dashed line) are shown. 


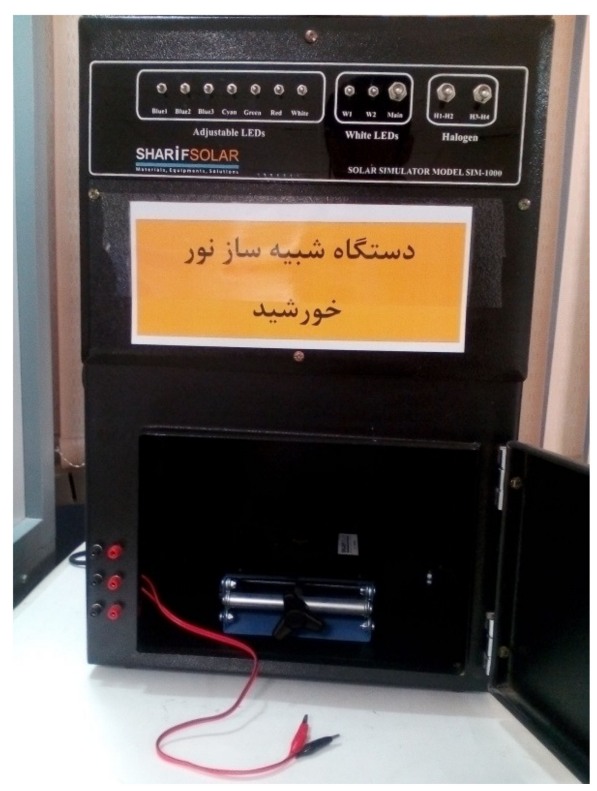

(a)

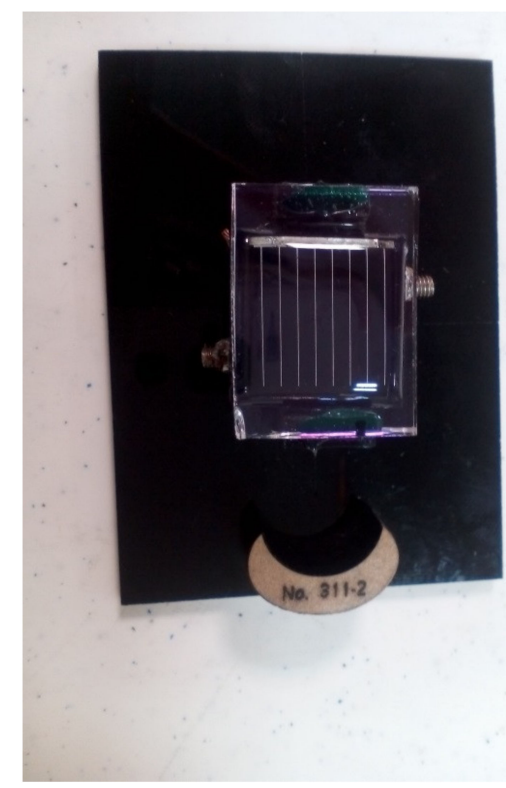

(b)

Figure 10. Experimental solar cell testing system (a) and a solar cell (b).

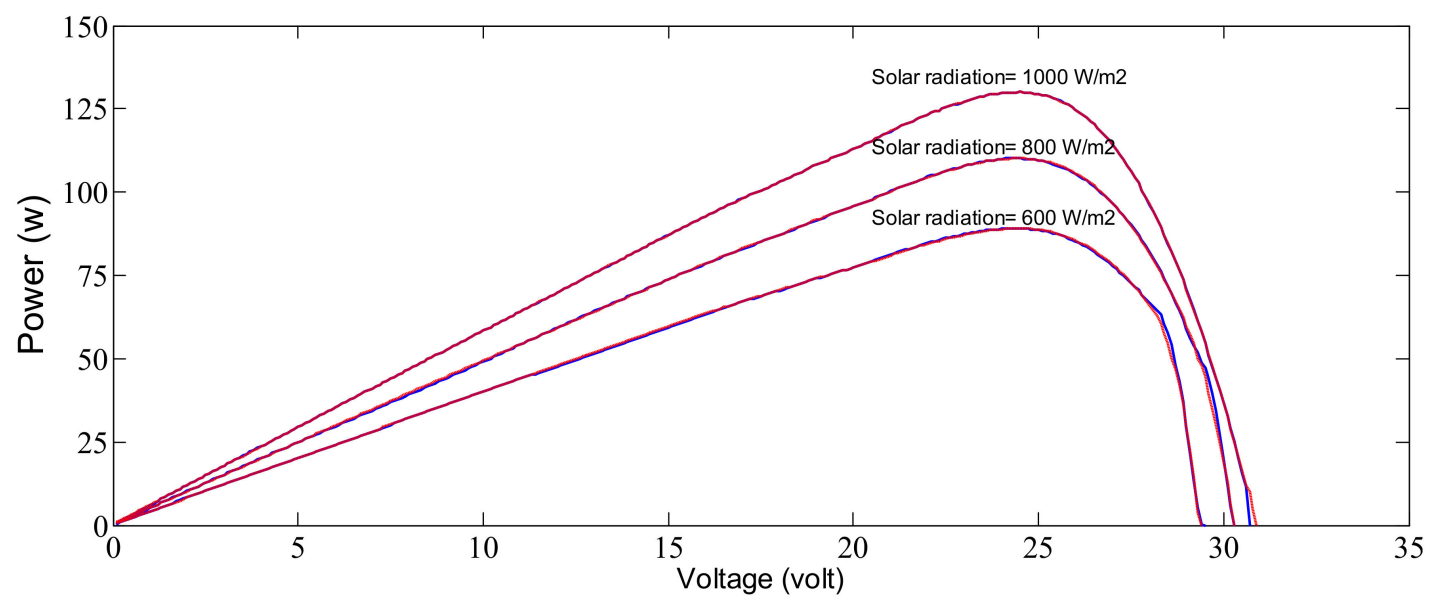

Figure 11. Identification results of the NCPRT2FS for solar cell.

After structure learning, for NCPRT2FS, three rules are generated and the RMSE value for the NCPRT2FS and IT2-TSK-FNN for the training and test are shown in Table 3. The final parameters are given in Table 3.

Table 3. The final values of NCPRT2FS parameters.

\begin{tabular}{|c|c|c|c|c|}
\hline \multirow{3}{*}{$\begin{array}{l}\text { Antecedent } \\
\text { parameters }\end{array}$} & & ${ }^{1} m_{i j}$ & ${ }^{2} m_{i j}$ & $\overline{\sigma_{i j}}$ \\
\hline & $\mathbf{u}(\mathbf{k})$ & $\begin{array}{l}{ }^{1} m_{11}=251 \\
{ }^{1} m_{21}=598 \\
{ }^{1} m_{31}=798\end{array}$ & $\begin{array}{l}{ }^{2} m_{11}=332 \\
{ }^{2} m_{21}=615 \\
{ }^{2} m_{31}=949\end{array}$ & $\begin{array}{c}\sigma_{11}=43 \\
\sigma_{21}=12 \\
\sigma_{31}=211\end{array}$ \\
\hline & $y(k-1)$ & $\begin{array}{l}{ }^{1} m_{12}=69 \\
{ }^{1} m_{22}=82 \\
{ }^{1} m_{32}=93\end{array}$ & $\begin{array}{l}{ }^{2} m_{12}=75 \\
{ }^{2} m_{22}=89 \\
{ }^{2} m_{32}=97\end{array}$ & $\begin{aligned} \sigma_{12} & =11 \\
\sigma_{22} & =5 \\
\sigma_{32} & =3\end{aligned}$ \\
\hline \multirow{3}{*}{$\begin{array}{l}\text { fourth layer } \\
\text { adaptive } \\
\text { weights }\end{array}$} & $\bar{w}_{r}^{1}=0.20$ & $\underline{w}_{\mathrm{r}}^{1}=0.06$ & $\bar{w}_{l}^{1}=0.12$ & $\underline{w}_{1}^{1}=0.09$ \\
\hline & $\bar{w}_{r}^{2}=1.80$ & $\underline{w}_{\mathrm{r}}^{2}=1.00$ & $\bar{w}_{l}^{2}=1.42$ & $\underline{w}_{1}^{2}=0.98$ \\
\hline & $\bar{w}_{r}^{3}=0.57$ & $\underline{w}_{\mathrm{r}}^{3}=0.21$ & $\bar{w}_{l}^{3}=1.93$ & $\underline{w}_{1}^{3}=1.10$ \\
\hline
\end{tabular}


Table 3. Cont.

\begin{tabular}{|c|c|c|c|c|c|c|}
\hline \multirow{12}{*}{$\begin{array}{l}\text { consequent } \\
\text { parameters }\end{array}$} & Rule 1 & Rule 2 & Rule 3 & Rule 1 & Rule 2 & Rule 3 \\
\hline & $s_{1,0}=0.10$ & $s_{2,0}=0.84$ & $s_{3,0}=1.00$ & $c_{1,0}=0.56$ & $c_{2,0}=1.00$ & $c_{3,0}=1.22$ \\
\hline & $s_{1,1}=0.32$ & $s_{2,1}=0.39$ & $s_{3,1}=0.37$ & $c_{1,1}=0.94$ & $c_{2,1}=1.60$ & $c_{3,1}=1.00$ \\
\hline & $s_{1,2}=1.00$ & $s_{2,2}=1.00$ & $s_{3,2}=0.61$ & $c_{1,2}=1.00$ & $c_{2,2}=1.00$ & $c_{3,2}=1.00$ \\
\hline & $s_{1,3}=0.22$ & $s_{2,3}=1.20$ & $s_{3,3}=0.50$ & $c_{1,3}=1.00$ & $c_{2,3}=1.77$ & $c_{3,3}=1.20$ \\
\hline & $s_{1,4}=0.10$ & $s_{2,4}=0.42$ & $s_{3,4}=1.00$ & $c_{1,4}=1.61$ & $c_{2,4}=0.60$ & $c_{3,4}=1.63$ \\
\hline & $s_{1,5}=0.47$ & $s_{2,5}=1.00$ & $s_{3,5}=1.00$ & $c_{1,5}=1.30$ & $c_{2,5}=1.00$ & $c_{3,5}=2.00$ \\
\hline & $s_{1,6}=0.10$ & $s_{2,6}=1.00$ & $s_{3,6}=1.00$ & $c_{1,6}=1.00$ & $c_{2,6}=1.11$ & $c_{3,6}=1.00$ \\
\hline & $s_{1,7}=1.20$ & $s_{2,7}=1.00$ & $s_{3,7}=0.19$ & $c_{1,7}=1.10$ & $c_{2,7}=1.50$ & $c_{3,7}=0.88$ \\
\hline & $s_{1,8}=1.00$ & $s_{2,8}=0.36$ & $s_{3,8}=0.69$ & $c_{1,8}=1.60$ & $c_{2,8}=0.89$ & $c_{3,8}=0.91$ \\
\hline & $s_{1,9}=1.00$ & $s_{2,9}=0.28$ & $s_{3,9}=0.11$ & $c_{1,9}=1.53$ & $c_{2,9}=0.95$ & $c_{3,9}=0.48$ \\
\hline & $s_{1,10}=0.55$ & $s_{2,10}=0.35$ & $s_{3,10}=0.50$ & $c_{1,10}=0.88$ & $c_{2,10}=1.00$ & $c_{3,10}=1.00$ \\
\hline
\end{tabular}

The trained NCPRT2FS is used to calculate the solar power of Ilam. Figure 12 shows the solar radiation of Ilam for a year. Figure 13 shows the predicted solar power in Ilam.

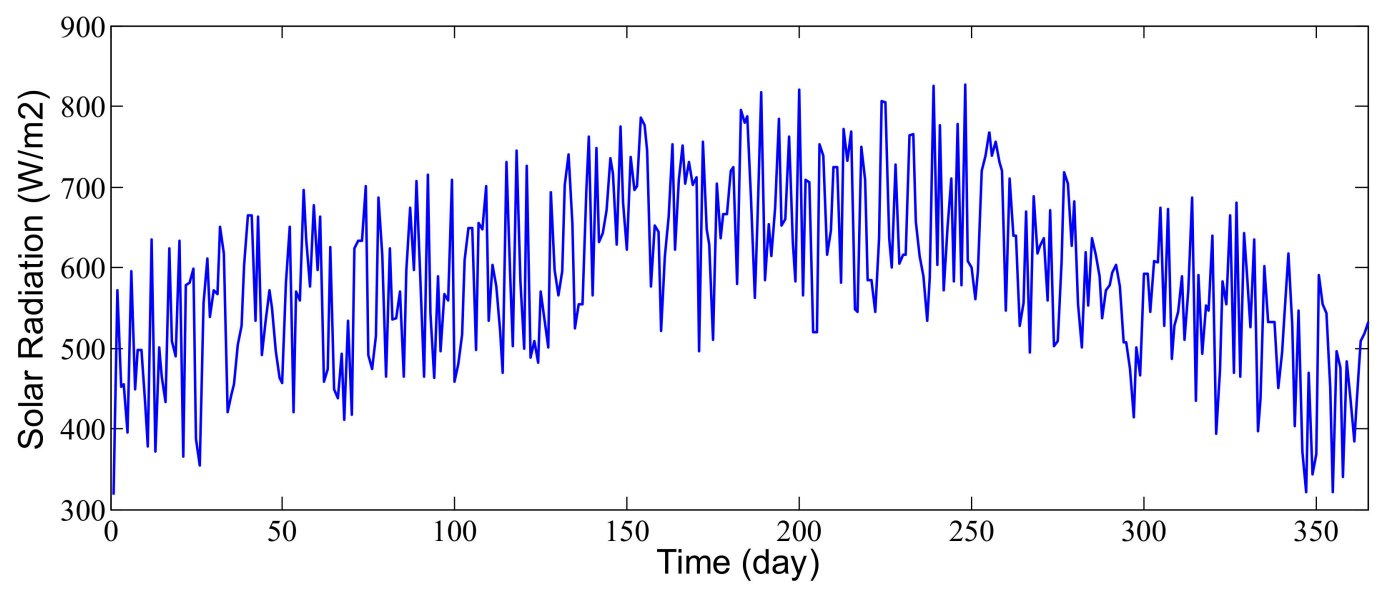

Figure 12. Solar radiation of Ilam.

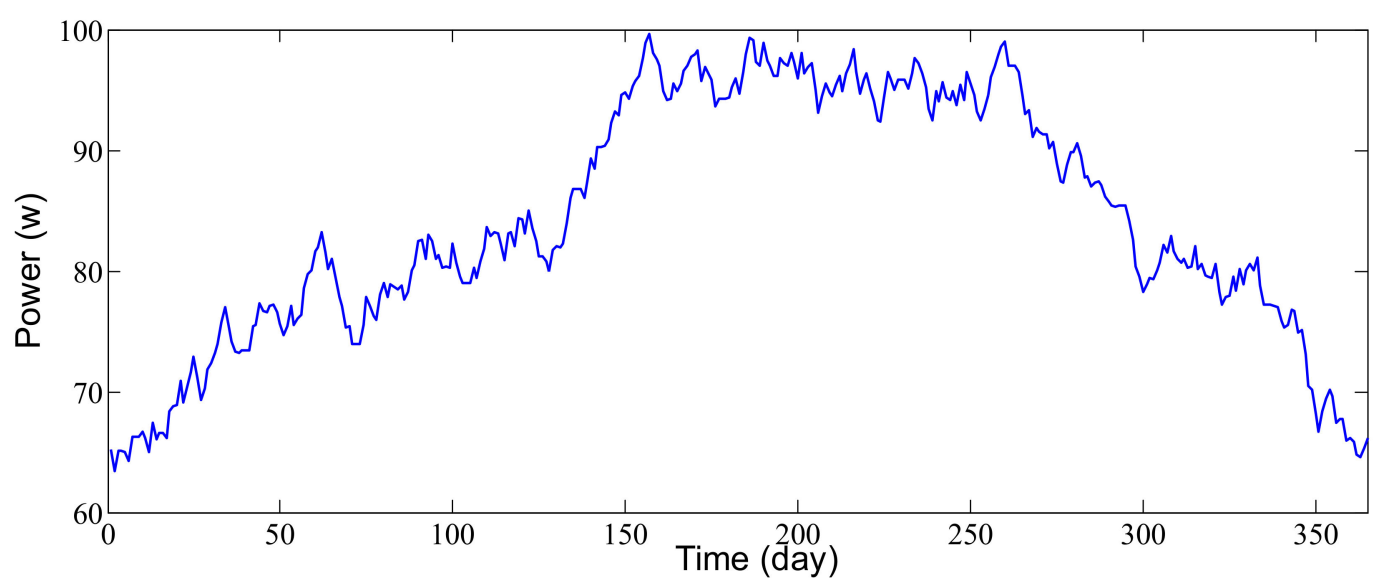

Figure 13. Predicted solar power in Ilam for a year.

Table 4. presents the comparison of our proposed method with another method (method of [46]). 
Table 4. Comparison between results of the proposed method and the method of [46].

\begin{tabular}{ccccccccc}
\hline \multirow{2}{*}{ Example } & \multicolumn{4}{c}{ Method of [46] } & \multicolumn{4}{c}{ Proposed NCPRT2FS } \\
\cline { 2 - 10 } & Rules & Epochs & Run Time (s) & RMSE & Rules & Epochs & Run Time (s) & RMSE \\
\hline 1 & 4 & 34 & 4 & 0.0159 & 4 & 31 & 6 & 0.0057 \\
\hline 2 & 5 & 27 & 4 & 0.00759 & 3 & 39 & 7 & 0.0013 \\
\hline
\end{tabular}

Simulations verify that the presented NCPRT2FS has high performances in function approximation and system identification. Table 4 shows that the number of rules of the proposed NCPRT2FS is almost less than the method of [53]; accuracy of identification is better than [53], but the training time in 10 runs (MATLAB 2011a; Dual CPU T3200 @ 2.00; RAM: $2.00 \mathrm{~GB} ; \mathrm{GHz} 2.00 \mathrm{GHz}$ ) is more than [53]. The references [23,46] presented two different $\mathrm{T} 2 \mathrm{~F}$ neural structures. They have also been used and evaluated only to identify some theory systems. In the present paper, however, the T2F neural network structure is different from references [23] and [53] and several experimental energy systems have been used for modeling.

\section{Conclusions}

In this paper, a novel Nonlinear Consequent Part Recurrent T2FS (NCPRT2FS) for identification and prediction of renewable energy systems was proposed. The nonlinear consequent part helps to better model highly nonlinear systems. Recurrent structure is a useful choice for the identification of dynamical systems. The self-evolving structure helps to obtain a simpler structure of the NCPRT2FS by ending up with a minimum number of fuzzy sets and fuzzy rules in the end. Simulations showed that the NCPRT2FS based on the backpropagation algorithm and adaptive optimization rate performs better than IT2-TSKFNN [53] in identification. An S47-660 kw wind turbine (VESTAS company Denmark) and a solar cell were selected as case studies. After data gathering, the proposed method was finally used with the experimental data for the purpose of identification. The RMSE was less than 0.006 and the number of fuzzy rules was equal and less than 4 rules; therefore, the results easily demonstrated the remarkable capability of the NCPRT2FS developed in the paper. In order to continue the work and look to the future, we can use the evolutionary algorithms as a complement to the proposed method for the development of the fuzzy neural network (to increase accuracy, increase convergence, etc.). Different case studies (types of solar cells, types of wind turbines, etc.) should be identified and the appropriate renewable system can be extracted for each geographical location.

Author Contributions: Writing-Original draft preparation, J.T., A.A.S., M.B.M., A.M. (Ardashir Mohammadzadeh), E.R., A.M. (Amir Mosavi); Software, J.T., A.A.S., M.B.M., A.M. (Ardashir Mohammadzadeh), E.R., A.M. (Amir Mosavi); Validation, J.T., A.A.S., M.B.M., A.M. (Ardashir Mohammadzadeh), E.R., A.M. (Amir Mosavi); Supervision, J.T., A.M. (Amir Mosavi). All authors have read and agreed to the published version of the manuscript.

Funding: This research received Open Access Funding by the Publication Fund of the TU Dresden.

Institutional Review Board Statement: Not applicable.

Informed Consent Statement: Not applicable.

Data Availability Statement: The data are available from via, (j.tavoosi@ilam.ac.ir), (accessed on 1 March 2021), upon reasonable request.

Conflicts of Interest: The authors declare that they have no conflict of interest. 
Sustainability 2021, 13, 3301

16 of 21

Appendix A

To update the consequent part parameters, Equations (A1)-(A20) are used.

$$
\begin{aligned}
& { }^{\text {new }}{ }^{c_{k, 0}}={ }^{\text {old }} c_{k, 0}+\eta \cdot 0.5 \cdot e_{p} \cdot\left[\frac{f_{l}^{k}}{\sum_{k=1}^{M} f_{l}^{k}}+\frac{f_{r}^{k}}{\sum_{k=1}^{M} f_{r}^{k}}\right] \\
& { }^{\text {new }} c_{k, i}={ }^{\text {old }} c_{k, i}+\eta \cdot 0.5 \cdot e_{p} \cdot\left[\frac{f_{l}^{k}}{\sum_{k=1}^{M} f_{l}^{k}}+\frac{f_{r}^{k}}{\sum_{k=1}^{M} f_{r}^{k}}\right] \cdot x_{i} \quad i=1,2 \\
& { }^{\text {new }} c_{k, 3}={ }^{\text {old }} c_{k, 3}+\eta \cdot 0.5 \cdot e_{p} \cdot\left[\frac{f_{l}^{k}}{\sum_{k=1}^{M} f_{l}^{k}}+\frac{f_{r}^{k}}{\sum_{k=1}^{M} f_{r}^{k}}\right] \cdot y(t-1) \\
& { }^{\text {new }} c_{k, 4}={ }^{\text {old }} c_{k, 4}+\eta \cdot 0.5 \cdot e_{p} \cdot\left[\frac{f_{l}^{k}}{\sum_{k=1}^{M} f_{l}^{k}}+\frac{f_{r}^{k}}{\sum_{k=1}^{M} f_{r}^{k}}\right] \cdot x_{1} \cdot x_{2} \\
& { }^{\text {new }} c_{k, 5}={ }^{\text {old }} c_{k, 5}+\eta \cdot 0.5 \cdot e_{p} \cdot\left[\frac{f_{l}^{k}}{\sum_{k=1}^{M} f_{l}^{k}}+\frac{f_{r}^{k}}{\sum_{k=1}^{M} f_{r}^{k}}\right] \cdot x_{1} \cdot y(t-1) \\
& { }^{\text {new }}{ }^{k, 6}={ }^{\text {old }} c_{k, 6}+\eta \cdot 0.5 \cdot e_{p} \cdot\left[\frac{f_{l}^{k}}{\sum_{k=1}^{M} f_{l}^{k}}+\frac{f_{r}^{k}}{\sum_{k=1}^{M} f_{r}^{k}}\right] \cdot x_{2} \cdot y(t-1) \\
& { }^{\text {new }} c_{k, 7}={ }^{\text {old }} c_{k, 7}+\eta \cdot 0.5 \cdot e_{p} \cdot\left[\frac{f_{l}^{k}}{\sum_{k=1}^{M} f_{l}^{k}}+\frac{f_{r}^{k}}{\sum_{k=1}^{M} f_{r}^{k}}\right] \cdot x_{1}^{2} \\
& { }^{\text {new }} c_{k, 8}={ }^{\text {old }} c_{k, 8}+\eta \cdot 0.5 \cdot e_{p} \cdot\left[\frac{f_{l}^{k}}{\sum_{k=1}^{M} f_{l}^{k}}+\frac{f_{r}^{k}}{\sum_{k=1}^{M} f_{r}^{k}}\right] \cdot x_{2}^{2} \\
& { }^{\text {new }} c_{k, 9}={ }^{\text {old }} c_{k, 9}+\eta \cdot 0.5 \cdot e_{p} \cdot\left[\frac{f_{l}^{k}}{\sum_{k=1}^{M} f_{l}^{k}}+\frac{f_{r}^{k}}{\sum_{k=1}^{M} f_{r}^{k}}\right] \cdot y^{2}(t-1) \\
& { }^{\text {new }}{ }^{k, 10}={ }^{\text {old }} c_{k, 10}+\eta \cdot 0.5 \cdot e_{p} \cdot\left[\frac{f_{l}^{k}}{\sum_{k=1}^{M} f_{l}^{k}}+\frac{f_{r}^{k}}{\sum_{k=1}^{M} f_{r}^{k}}\right] \cdot x_{1} \cdot x_{2} \cdot y(t-1) \\
& { }^{\text {new }}{ }_{S_{k, 0}}={ }^{\text {old }}{ }_{S_{k, 0}}+\eta \cdot 0.5 \cdot e_{p} \cdot\left[\frac{f_{l}^{k}}{\sum_{k=1}^{M} f_{l}^{k}}-\frac{f_{r}^{k}}{\sum_{k=1}^{M} f_{r}^{k}}\right] \\
& { }^{\text {new }}{ }_{S_{k, i}}={ }^{\text {old }}{ }_{S_{k, i}}+\eta \cdot 0.5 \cdot e_{p} \cdot\left[\frac{f_{l}^{k}}{\sum_{k=1}^{M} f_{l}^{k}}-\frac{f_{r}^{k}}{\sum_{k=1}^{M} f_{r}^{k}}\right] \cdot\left|x_{i}\right| i=1,2 \\
& { }^{\text {new }} s_{k, 3}={ }^{\text {old }} s_{k, 3}+\eta \cdot 0.5 \cdot e_{p} \cdot\left[\frac{f_{l}^{k}}{\sum_{k=1}^{M} f_{l}^{k}}-\frac{f_{r}^{k}}{\sum_{k=1}^{M} f_{r}^{k}}\right] \cdot|y(t-1)| \\
& { }^{\text {new }}{ }_{S_{k, 4}}={ }^{\text {old }}{ }_{k, 4}+\eta \cdot 0.5 \cdot e_{p} \cdot\left[\frac{f_{l}^{k}}{\sum_{k=1}^{M} f_{l}^{k}}-\frac{f_{r}^{k}}{\sum_{k=1}^{M} f_{r}^{k}}\right] \cdot\left|x_{1} x_{2}\right| \\
& { }_{\text {new }} S_{k, 5}={ }^{\text {old }} S_{k, 5}+\eta \cdot 0.5 \cdot e_{p} \cdot\left[\frac{f_{l}^{k}}{\sum_{k=1}^{M} f_{l}^{k}}-\frac{f_{r}^{k}}{\sum_{k=1}^{M} f_{r}^{k}}\right] \cdot\left|x_{1} \cdot y(t-1)\right| \\
& { }^{\text {new }}{ }_{S_{k, 6}}={ }^{\text {old }} S_{k, 6}+\eta \cdot 0.5 \cdot e_{p} \cdot\left[\frac{f_{l}^{k}}{\sum_{k=1}^{M} f_{l}^{k}}-\frac{f_{r}^{k}}{\sum_{k=1}^{M} f_{r}^{k}}\right] \cdot\left|x_{2} \cdot y(t-1)\right| \\
& { }^{\text {new }}{ }_{k, 7}={ }^{\text {old }} s_{k, 7}+\eta \cdot 0.5 \cdot e_{p} \cdot\left[\frac{f_{l}^{k}}{\sum_{k=1}^{M} f_{l}^{k}}-\frac{f_{r}^{k}}{\sum_{k=1}^{M} f_{r}^{k}}\right] \cdot x_{1}^{2}
\end{aligned}
$$

(A17) 


$$
\begin{gathered}
{ }^{\text {new }} s_{k, 8}={ }^{\text {old }} s_{k, 8}+\eta \cdot 0.5 \cdot e_{p} \cdot\left[\frac{f_{l}^{k}}{\sum_{k=1}^{M} f_{l}^{k}}-\frac{f_{r}^{k}}{\sum_{k=1}^{M} f_{r}^{k}}\right] \cdot x_{2}^{2} \\
{ }^{\text {eww }} s_{k, 9}={ }^{\text {old }} s_{k, 9}+\eta \cdot 0.5 \cdot e_{p} \cdot\left[\frac{f_{l}^{k}}{\sum_{k=1}^{M} f_{l}^{k}}-\frac{f_{r}^{k}}{\sum_{k=1}^{M} f_{r}^{k}}\right] \cdot y^{2}(t-1) \\
{ }^{\text {new }} s_{k, 10}={ }^{\text {old }} s_{k, 10}+\eta \cdot 0.5 \cdot e_{p} \cdot\left[\frac{f_{l}^{k}}{\sum_{k=1}^{M} f_{l}^{k}}-\frac{f_{r}^{k}}{\sum_{k=1}^{M} f_{r}^{k}}\right] \cdot\left|x_{1} \cdot x_{2} \cdot y(t-1)\right|
\end{gathered}
$$

The learning rate is indicated by $\eta$.

To update the left and right weights, Equations (A21)-(A24) are used.

$$
\begin{aligned}
& { }^{n e w} \underline{w}_{l}^{k}={ }^{o l d} \underline{w}_{l}^{k}+\eta \cdot 0.5 \cdot e_{p} \cdot \frac{y_{l}^{k}-\hat{y}_{l}}{\sum_{j=1}^{M} f_{l}^{j}} \cdot \frac{f^{k}-f_{l}^{k}}{\bar{w}_{l}^{k}+\underline{w}_{l}^{k}} \\
& { }^{n e w} \bar{w}_{l}^{k}={ }^{\text {old }} \bar{w}_{l}^{k}+\eta \cdot 0.5 \cdot e_{p} \cdot \frac{y_{l}^{k}-\hat{y}_{l}}{\sum_{j=1}^{M} f_{l}^{j}} \cdot \frac{\bar{f}^{k}-f_{l}^{k}}{\bar{w}_{l}^{k}+\underline{w}_{l}^{k}} \\
& { }^{n e w} \underline{w}_{r}^{k}={ }^{o l d} \underline{w}_{r}^{k}+\eta \cdot 0.5 \cdot e_{p} \cdot \frac{y_{r}^{k}-\hat{y}_{r}}{\sum_{j=1}^{M} f_{r}^{j}} \cdot \frac{f^{k}-f_{r}^{k}}{\bar{w} w_{r}^{k}+\underline{w}_{r}^{k}} \\
& { }^{n e w} \bar{w}_{r}^{k}={ }^{o l d} \bar{w}_{r}^{k}+\eta \cdot 0.5 \cdot e_{p} \cdot \frac{y_{r}^{k}-\hat{y}_{r}}{\sum_{j=1}^{M} f_{r}^{j}} \cdot \frac{\bar{f}^{k}-f_{r}^{k}}{\bar{w}_{r}^{k}+\underline{w}_{r}^{k}}
\end{aligned}
$$

Finally, the equations for updating the antecedent parameters can be described as follows:

$$
\begin{gathered}
{ }^{1} m_{k, i}^{\text {new }}={ }^{1} m_{k, i}^{\text {old }}+\eta \cdot 0.5 \cdot e_{p} \cdot\left[\frac{y_{l}^{k}-\hat{y}_{l}}{\sum_{j=1}^{M} f_{l}^{j}} \cdot \frac{\partial f_{l}^{k}}{\partial^{1} m_{k, i}}+\frac{y_{r}^{k}-\hat{y}_{r}}{\sum_{j=1}^{M} f_{r}^{j}} \cdot \frac{\partial f_{r}^{k}}{\partial^{1} m_{k, i}}\right] \\
{ }^{2} m_{k, i}^{\text {new }}={ }^{2} m_{k, i}^{\text {old }}+\eta \cdot 0.5 \cdot e_{p} \cdot\left[\frac{y_{l}^{k}-\hat{y}_{l}}{\sum_{j=1}^{M} f_{l}^{j}} \cdot \frac{\partial f_{l}^{k}}{\partial^{2} m_{k, i}}+\frac{y_{r}^{k}-\hat{y}_{r}}{\sum_{j=1}^{M} f_{r}^{j}} \cdot \frac{\partial f_{r}^{k}}{\partial^{2} m_{k, i}}\right] \\
\sigma_{k \cdot i}^{\text {new }}=\sigma_{k \cdot i}^{\text {old }}+\eta \cdot 0.5 \cdot e_{p} \cdot\left[\frac{y_{l}^{k}-\hat{y}_{l}}{\sum_{j=1}^{M} f_{l}^{j}} \cdot \frac{\partial f_{l}^{k}}{\partial \sigma_{k, i}}+\frac{y_{r}^{k}-\hat{y}_{r}}{\sum_{j=1}^{M} f_{r}^{j}} \cdot \frac{\partial f_{r}^{k}}{\partial \sigma_{k, i}}\right]
\end{gathered}
$$

where

$$
\begin{aligned}
\frac{\partial f_{l}^{k}}{\partial m_{k, i}} & =\frac{\bar{w}_{l}^{k} \cdot\left[\bar{f}^{k}-{ }^{2} \mu_{k, i} \cdot \prod_{l=1, l \neq i}^{n}\left(\bar{\mu}_{k, l}\right)\right]+\underline{w}_{l}^{k} \cdot \underline{f}^{k}}{\bar{w}_{l}^{k}+\underline{w}_{l}^{k}} \cdot \frac{x_{i}-{ }^{1} m_{k, i}}{\left(\sigma_{k, i}\right)^{2}} \\
\frac{\partial f_{l}^{k}}{\partial^{2} m_{k, i}} & =\frac{\bar{w}_{l}^{k} \cdot\left[\bar{f}^{k}-{ }^{1} \mu_{k, i} \cdot \prod_{l=1, l \neq i}^{n}\left(\bar{\mu}_{k, l}\right)\right]+\underline{w}_{l}^{k} \cdot \underline{f}^{k}}{\bar{w}_{l}^{k}+\underline{w}_{l}^{k}} \cdot \frac{x_{i}-{ }^{2} m_{k, i}}{\left(\sigma_{k, i}\right)^{2}} \\
\frac{\partial f_{l}^{k}}{\partial \sigma_{k, i}} & =\frac{\bar{w}_{l}^{k} \cdot\left[\left(\bar{f}^{k}-{ }^{2} \mu_{k, i} \cdot \prod_{l=1, l \neq i}^{n}\left(\bar{\mu}_{k, l}\right)\right) \cdot \frac{\left(x_{i}-1 m_{k, i}\right)^{2}}{\left(\sigma_{k, i}\right)^{3}}\right]}{\bar{w}_{l}^{k}+\underline{w}_{l}^{k}} \\
& +\frac{\bar{w}_{l}^{k} \cdot\left[\left(\bar{f}^{k}-{ }^{1} \mu_{k, i} \cdot \prod_{l=1, l \neq i}^{n}\left(\bar{\mu}_{k, l}\right)\right) \cdot \frac{\left(x_{i}-{ }^{2} m_{k, i}\right)^{2}}{\left(\sigma_{k, i}\right)^{3}}\right]}{\bar{w}_{l}^{k}+\underline{w}_{l}^{k}}
\end{aligned}
$$




$$
\begin{aligned}
& +\frac{\underline{w}_{l}^{k} \cdot \underline{f}^{k} \cdot\left[\frac{\left(x_{i}-{ }^{1} m_{k, i}\right)^{2}+\left(x_{i}-{ }^{2} m_{k, i}\right)^{2}}{\left(\sigma_{k, i}\right)^{3}}\right]}{\bar{w}_{l}^{k}+\underline{w}_{l}^{k}} \\
& \frac{\partial f_{r}^{k}}{\partial^{1} m_{k, i}}=\frac{\bar{w}_{r}^{k} \cdot\left[\bar{f}^{k}-{ }^{2} \mu_{k, i} \cdot \prod_{l=1, l \neq i}^{n}\left(\bar{\mu}_{k, l}\right)\right]+\underline{w}_{r}^{k} \cdot \underline{f}^{k}}{\bar{w}_{r}^{k}+\underline{w}_{r}^{k}} \cdot \frac{x_{i}-{ }^{1} m_{k, i}}{\left(\sigma_{k, i}\right)^{2}} \\
& \frac{\partial f_{r}^{k}}{\partial^{2} m_{k, i}}=\frac{\bar{w}_{r}^{k} \cdot\left[\bar{f}^{k}-{ }^{1} \mu_{k, i} \cdot \prod_{l=1, l \neq i}^{n}\left(\bar{\mu}_{k, l}\right)\right]+\underline{w}_{r}^{k} \cdot \underline{f}^{k}}{\bar{w}_{r}^{k}+\underline{w}_{r}^{k}} \cdot \frac{x_{i}-{ }^{2} m_{k, i}}{\left(\sigma_{k, i}\right)^{2}} \\
& \frac{\partial f_{r}^{k}}{\partial \sigma_{k, i}}=\frac{\bar{w}_{r}^{k} \cdot\left[\left(\bar{f}^{k}-{ }^{2} \mu_{k, i} \cdot \prod_{l=1, l \neq i}^{n}\left(\bar{\mu}_{k, l}\right)\right) \cdot \frac{\left(x_{i}-{ }^{1} m_{k, i}\right)^{2}}{\left(\sigma_{k, i}\right)^{3}}\right]}{\bar{w}_{r}^{k}+\underline{w}_{r}^{k}} \\
& +\frac{\bar{w}_{r}^{k} \cdot\left[\left(\bar{f}^{k}-{ }^{1} \mu_{k, i} \cdot \prod_{l=1, l \neq i}^{n}\left(\bar{\mu}_{k, l}\right)\right) \cdot \frac{\left(x_{i}-{ }^{2} m_{k, i}\right)^{2}}{\left(\sigma_{k, i}\right)^{3}}\right]}{\bar{w}_{r}^{k}+\underline{w}_{r}^{k}} \\
& +\frac{\underline{w}_{r}^{k} \cdot \underline{f}^{k} \cdot\left[\frac{\left(x_{i}-{ }^{1} m_{k, i}\right)^{2}+\left(x_{i}-{ }^{2} m_{k, i}\right)^{2}}{\left(\sigma_{k, i}\right)^{3}}\right]}{\bar{w}_{r}^{k}+\underline{w}_{r}^{k}}
\end{aligned}
$$

Convergence Analysis of Learning Algorithm

The Lyapunov function is used to guarantee learning algorithm convergence. The Lyapunov function is defined as

$$
V_{p}(k)=E_{p}(k)=\frac{1}{2} e_{p}^{2}(k)=\frac{1}{2}\left(t_{p}(k)-\hat{y}_{p}(k)\right)^{2}
$$

Equation (A35) shows the Lyapunov function changes.

$$
\Delta V_{p}(k)=V_{p}(k+1)-V_{p}(k)=\frac{1}{2}\left(e_{p}^{2}(k+1)-e_{p}^{2}(k)\right)
$$

Next, the moment error is calculated from Equation (A36).

$$
e_{p}(k+1)=e_{p}(k)+\Delta e_{p}(k) \cong e_{p}(k)+\left[\frac{\partial e_{p}(k)}{\partial W}\right]^{T} \Delta W
$$

In Equation (A36), $\Delta W$ is parameter changing, where $W=\left[\sigma_{k, i},{ }^{1} m_{k, i},{ }^{2} m_{k, i}, c_{k, i}, s_{k, i}\right]$. In Equation (A37), the general form of gradient-based updating is presented.

$$
W(k+1)=W(k)+\Delta W(k)=W(k)+\eta \cdot\left(-\frac{\partial E_{p}(k)}{\partial W}\right)
$$

where

$$
\frac{\partial E_{p}(k)}{\partial W}=-e_{p}(k) \cdot \frac{\partial \hat{y}}{\partial W}
$$

Equation (A35) can be rewritten as Equation (A39).

$$
\begin{gathered}
\Delta V_{p}(k)=\frac{1}{2}\left(e_{p}^{2}(k+1)-e_{p}^{2}(k)\right) \\
=\frac{1}{2}\left[\left(e_{p}(k+1)-e_{p}(k)\right)\right] \cdot\left[\left(e_{p}(k+1)+e_{p}(k)\right)\right] \\
=\frac{1}{2} \Delta e_{p}(k)\left[2\left(e_{p}(k)\right)+\Delta e_{p}(k)\right]
\end{gathered}
$$




$$
\begin{gathered}
=\frac{1}{2} \Delta e_{p}(k)\left[2\left(e_{p}(k)\right)+\Delta e_{p}(k)\right] \\
=\left[\frac{\partial e_{p}(k)}{\partial W}\right]^{T} \cdot \eta \cdot e_{p}(k) \cdot \frac{\partial \hat{y}(k)}{\partial W} \cdot\left\{e_{p}(k)+\frac{1}{2}\left[\frac{\partial e_{p}(k)}{\partial W}\right]^{T} \cdot \eta \cdot e_{p}(k) \cdot \frac{\partial \hat{y}(k)}{\partial W}\right\} \\
=-\left[\frac{\partial \hat{y}(k)}{\partial W}\right]^{T} \cdot \eta \cdot e_{p}(k) \cdot \frac{\partial \hat{y}(k)}{\partial W} \cdot\left\{e_{p}(k)-\frac{1}{2}\left[\frac{\partial \hat{y}(k)}{\partial W}\right]^{T} \cdot \eta \cdot e_{p}(k) \cdot \frac{\partial \hat{y}(k)}{\partial W}\right\} \\
=-\eta \cdot\left(e_{p}(k)\right)^{2}\left|\frac{\partial \hat{y}(k)}{\partial W}\right|^{2} \cdot\left[1-\frac{1}{2} \eta \cdot\left|\frac{\partial \hat{y}(k)}{\partial W}\right|^{2}\right]
\end{gathered}
$$

In order for $\Delta V_{p}(k)<0$, then:

$$
0<\eta<\frac{2}{\max \left|\frac{\partial \hat{y}(k)}{\partial W}\right|^{2}}
$$

If (A40) holds for every parameter $W=\left[\sigma_{k, i},{ }^{1} m_{k, i},{ }^{2} m_{k, i}, c_{k, i}, s_{k, i}\right]$, then the algorithm is definitely convergent.

\section{References}

1. Quaranta, G.; Lacarbonara, W.; Masri, S.F. A review on computational intelligence for identification of nonlinear dynamical systems. Nonlinear Dyn. 2020, 99, 1709-1761. [CrossRef]

2. Andrukhiv, A.; Sokil, M.; Fedushko, S.; Syerov, Y.; Kalambet, Y.; Peracek, T. Methodology for increasing the efficiency of dynamic process calculations in elastic elements of complex engineering constructions. Electronics 2021, 10, 40. [CrossRef]

3. Shekhovtsov, A.; Kołodziejczyk, J.; Sałabun, W. Fuzzy Model identification using monolithic and structured approaches in decision problems with partially incomplete data. Symmetry 2020, 12, 1541. [CrossRef]

4. Mombeini, H.; Yazdani-Chamzini, A.; Streimikiene, D.; Zavadskas, E.K. New fuzzy logic approach for the capability assessment of renewable energy technologies: Case of Iran. Energy Environ. 2018, 29, 511-532. [CrossRef]

5. Sakthivel, K.; Devaraj, B.; Banu, D.; Narmatha Selvi, R.; Agnes Idhaya, V. A hybrid wind-solar energy system with ANFIS based MPPT controller. J. Intell. Fuzzy Syst. 2018, 35, 1579-1595.

6. Shuli, L.; Xinwang, L.; Dongwei, L. A prospect theory based MADM method for solar water heater selection problems. J. Intell. Fuzzy Syst. 2017, 32, 1855-1865.

7. Kaid, I.E.; Hafaifa, A.; Guemana, M.; Hadroug, N.; Kouzou, A.; Mazouz, L. Photovoltaic system failure diagnosis based on adaptive neuro fuzzy inference approach: South Algeria solar power plant. J. Clean. Prod. 2018, 204, 169-182. [CrossRef]

8. Samanlioglu, F.; Ayağ, Z. A fuzzy AHP-PROMETHEE II approach for evaluation of solar power plant location alternatives in Turkey. J. Intell. Fuzzy Syst. 2017, 33, 859-871. [CrossRef]

9. Grahovac, J.; Jokic, A.; Dodic, J.; Vucurovic, D.; Dodic, S. Modelling and prediction of bioethanol production from intermediates and byproduct of sugar beet processing using neural networks. Renew. Energy 2016, 85, 953-958. [CrossRef]

10. Khiareddine, A.; Salah, C.B.; Mimouni, M.F. Power management of a photovoltaic/battery pumping system in agricultural experiment station. Sol. Energy 2015, 112, 319-338. [CrossRef]

11. Osorio, G.J.; Matias, J.C.O.; Catalao, J.P.S. Short-term wind power forecasting using adaptive neuro-fuzzy inference system combined with evolutionary particle swarm optimization, wavelet transform and mutual information. Renew. Energy 2015, 75, 301-307. [CrossRef]

12. Etemadi, M.; Abdollahi, A.; Rashidinejad, M.; Aalami, H.A. Wind turbine output power prediction in a probabilistic framework based on fuzzy intervals. Iran J. Sci. Technol. Trans. Electr. Eng. 2021, 45, 131-139. [CrossRef]

13. Torshizi, A.D.; Fazel Zarandi, M.H. A new cluster validity measure based on general type-2 fuzzy sets: Application in gene expression data clustering. Knowl. Based Syst. 2014, 64, 81-93. [CrossRef]

14. Hesarian, M.S.; Tavoosi, J.; Hosseini, S.H. Neuro-fuzzy modelling and experimental study of the physiological comfort of green cotton fabric based on yarn properties. Int. J. Eng. 2020, 33, 2443-2449. [CrossRef]

15. Tavoosi, J. A new type-2 fuzzy sliding mode control for longitudinal aerodynamic parameters of a commercial aircraft. J. Eur. Des. Systèmes Autom. 2020, 53, 479-485. [CrossRef]

16. Lu, W.; Yang, J.; Liu, X.; Pedrycz, W. The modeling and prediction of time series based on synergy of high-order fuzzy cognitive map and fuzzy c-means clustering. Knowl. Based Syst. 2014, 70, 242-255. [CrossRef]

17. Abiyev, R.H.; Kaynak, O.; Kayacan, E. A type-2 fuzzy wavelet neural network for system identification and control. J. Frankl. Inst. 2013, 350, 1658-1685. [CrossRef]

18. Wang, H.; Luo, C.; Wang, X. Synchronization and identification of nonlinear systems by using a novel self-evolving interval type-2 fuzzy LSTM-neural network. Eng. Appl. Artif. Intell. 2019, 81, 79-93. [CrossRef] 
19. Luo, C.; Tan, C.; Wang, X.; Zheng, Y. An evolving recurrent interval type-2 intuitionistic fuzzy neural network for online learning and time series prediction. Appl. Soft Comput. 2019, 78, 150-163. [CrossRef]

20. El-Nagar, A. Nonlinear dynamic systems identification using recurrent interval type-2 TSK fuzzy neural network-A novel structure. ISA Trans. 2018, 72, 205-217. [CrossRef]

21. Tavoosi, J.; Suratgar, A.A.; Menhaj, M.B. Nonlinear system identification based on a self-organizing type-2 fuzzy RBFN. Eng. Appl. Artif. Intell. 2016, 54, 26-38. [CrossRef]

22. Anh, N.; Suresh, S.; Pratama, M.; Srikanth, N. Interval prediction of wave energy characteristics using meta-cognitive interval type-2 fuzzy inference system. Knowl. Based Syst. 2019, 169, 28-38. [CrossRef]

23. Tavoosi, J.; Suratgar, A.A.; Menhaj, M.B. Stable ANFIS2 for Nonlinear System Identification. Neurocomputing 2016, 182, 235-246. [CrossRef]

24. Ali, F.; Kim, E.K.; Kim, Y.G. Type-2 fuzzy ontology-based semantic knowledge for collision avoidance of autonomous underwater vehicles. Inf. Sci. 2015, 295, 441-464. [CrossRef]

25. Sun, Z.; Wang, N.; Bi, Y. Type-1/type-2 fuzzy logic systems optimization with RNA genetic algorithm for double inverted pendulum. Appl. Math. Model. 2015, 39, 70-85. [CrossRef]

26. Khooban, M.H.; Alfi, A.; Abadi, D.N.M. Control of a class of non-linear uncertain chaotic systems via an optimal Type-2 fuzzy proportional integral derivative controller. IET Sci. Meas. Technol. 2013, 7, 50-58. [CrossRef]

27. Lee, C.H.; Chang, F.Y.; Lin, C.M. An efficient interval type-2 fuzzy CMAC for chaos time-series prediction and synchronization. IEEE Trans. Cybern. 2014, 44, 329-341. [CrossRef] [PubMed]

28. Yu, W.S.; Chen, H.S. Interval type-2 fuzzy adaptive tracking control design for PMDC motor with the sector dead-zones. Inf. Sci. 2014, 288, 108-134. [CrossRef]

29. Esposito, M.; Pietro, G.D. Interval type-2 fuzzy logic for encoding clinical practice guidelines. Knowl. Based Syst. 2013, 54, 329-341. [CrossRef]

30. Lin, Y.Y.; Chang, J.Y.; Pal, N.R.; Lin, C.T. A Mutually recurrent interval Type-2 neural fuzzy system (MRIT2NFS) with self-evolving structure and parameters. IEEE Trans. Fuzzy Syst. 2013, 21, 492-509. [CrossRef]

31. Tavoosi, J. A new Type-2 fuzzy systems for flexible-joint robot arm control. Aut J. Model. Simul. 2019, 51. [CrossRef]

32. Asad, Y.P.; Shamsi, A.; Ivani, H.; Tavoosi, J. Adaptive intelligent inverse control of nonlinear systems with regard to sensor noise and parameter uncertainty (magnetic ball levitation system case study). Int. J. Smart Sens. Intell. Syst. 2016, 9, 148-169.

33. Tavoosi, J.; Badamchizadeh, M.A.; Ghaemi, S. Adaptive inverse control of nonlinear dynamical system using Type-2 fuzzy neural networks. J. Control 2011, 5, 52-60.

34. Fazlya, M.; Pedram, M.Z.; Salarieh, H.; Alasty, A. Parameter estimation and interval type-2 fuzzy sliding mode control of a z-axis MEMS gyroscope. ISA Trans. 2013, 52, 900-911. [CrossRef] [PubMed]

35. Melin, P.; Castillo, O. A review on type-2 fuzzy logic applications in clustering, classification and pattern recognition. Appl. Soft Comput. 2014, 21, 568-577. [CrossRef]

36. Wu, G.D.; Zhu, Z.W. An enhanced discriminability recurrent fuzzy neural network for temporal classification problems. Fuzzy Sets Syst. 2014, 237, 47-62. [CrossRef]

37. Tavoosi, J.; Mohammadzadeh, A. A new recurrent radial basis function network-based model predictive control for a power plant boiler temperature control. Int. J. Eng. 2021, 34, 667-675.

38. Moodi, H.; Farrokhi, M. Robust observer design for Sugeno systems with incremental quadratic nonlinearity in the consequent. Int. J. Appl. Math. Comput. Sci. 2013, 23, 711-723. [CrossRef]

39. Tavoosi, J. A novel recurrent Type-2 fuzzy neural network stepper motor control. Mechatron. Syst. Control 2021, 49. [CrossRef]

40. Tavoosi, J.; Mohammadi, F. A new Type-II fuzzy system for flexible-joint robot arm control. In Proceedings of the 6th International Conference on Control, Instrumentation and Automation (ICCIA), Sanandaj, Iran, 30-31 October 2019; pp. 1-4. [CrossRef]

41. Tavoosi, J.; Mohammadi, F. A 3-PRS parallel robot control based on Fuzzy-PID controller. In Proceedings of the 6th International Conference on Control, Instrumentation and Automation (ICCIA), Sanandaj, Iran, 30-31 October 2019; pp. 1-4. [CrossRef]

42. Tavoosi, J.; Azami, R. A New Method for controlling the speed of a surface permanent magnet synchronous motor using fuzzy comparative controller with hybrid learning. Comput. Intell. Electr. Eng. 2019, 10, 57-68.

43. Tavoosi, J. An experimental study on inverse adaptive neural fuzzy control for nonlinear systems, International. J. Knowl. Based Intell. Eng. Syst. 2020, 24, 135-143. [CrossRef]

44. Tavoosi, J. Stable backstepping sliding mode control Based on ANFIS2 for a class of nonlinear systems. Jordan J. Electr. Eng. 2020, 6, 49-62. [CrossRef]

45. Tavoosi, J. Sliding mode control of a class of nonlinear systems based on recurrent type-2 fuzzy RBFN. Int. J. Mechatron. Autom. 2020, 7, 230-240.

46. Tavoosi, J. Hybrid intelligent adaptive controller for tiltrotor UAV. Int. J. Intell. Unmanned Syst. 2020, in press. [CrossRef]

47. Tavoosi, J.; Badamchizadeh, M.A. A class of type-2 fuzzy neural networks for nonlinear dynamical system identification. Neural Comput. Appl. 2013, 23, 707-717. [CrossRef]

48. Tavoosi, J.; Suratgar, A.A.; Menhaj, M.B. Stability analysis of recurrent type-2 TSK fuzzy systems with nonlinear consequent part. Neural Comput. Appl. 2017, 28, 47-56. [CrossRef]

49. Tavoosi, J.; Suratgar, A.A.; Menhaj, M.B. Stability analysis of a class of MIMO recurrent type-2 fuzzy systems. Int. J. Fuzzy Syst. 2017, 19, 895-908. [CrossRef] 
50. Jahangiri, F.; Doustmohammadi, A.; Menhaj, M.B. An adaptive wavelet differential neural networks based identifier and its stability analysis. Neurocomputing 2012, 77, 12-19. [CrossRef]

51. Suratgar, A.A.; Nikravesh, S.K. A new method for linguistic modeling with stability analysis and applications. Intell. Autom. Soft Comput. 2009, 15, 329-342. [CrossRef]

52. Li, C.; Wang, L.; Zhang, G.; Wang, H.; Shang, F. Functional-type single-input-rule-modules connected neural fuzzy system for wind speed prediction. J. Autom. Sin. 2017, 4, 751-762. [CrossRef]

53. Karakuş, O.; Kuruoğlu, E.E.; Altınkaya, M.A. One-day ahead wind speed/power prediction based on polynomial autoregressive model. IET Renew. Power Gener. 2017, 11, 1430-1439. [CrossRef]

54. Tian, Y.; Wang, B.; Zhu, D.; Wu, F. Takagi-Sugeno fuzzy generalised predictive control of a time-delay non-linear hydro-turbine governing system. IET Renew. Power Gener. 2019, 13, 2338-2345. [CrossRef]

55. Morshedizadeh, M.; Kordestani, M.; Carriveau, R.; Ting, D.S.; Saif, M. Power production prediction of wind turbines using a fusion of MLP and ANFIS networks. IET Renew. Power Gener. 2018, 12, 1025-1033. [CrossRef]

56. Castro, J.R.; Castillo, O.; Martínez, L.G. Interval Type-2 Fuzzy Logic Toolbox. Eng. Lett. 2007, $15,1$.

57. Mendel, J.M. Uncertain Rule-Based Fuzzy Logic Systems: Introduction and New Directions; Prentice-Hall: Upper New Jersey River, NJ, USA, 2001

58. Mendel, J.M. Advances in type-2 fuzzy sets and systems. Inf. Sci. 2007, 177, 84-110. [CrossRef]

59. Kizielewicz, B.; Sałabun, W. A new approach to identifying a multi-criteria decision model based on stochastic optimization techniques. Symmetry 2020, 12, 1551. [CrossRef]

60. Karnik, N.N.; Mendel, J.M.; Liang, Q. Type-2 fuzzy logic systems. IEEE Trans. Fuzzy Syst. 1999, 7, 643-658. [CrossRef]

61. Singh, M.; Srivastava, S.; Hanmandlu, M.; Gupta, J.R.P. Type-2 fuzzy wavelet networks (T2FWN) for system identification using fuzzy differential and Lyapunov stability algorithm. Appl. Soft Comput. 2009, 9, 977-989. [CrossRef]

62. Juang, C.F.; Lin, Y.Y.; Tu, C.C. A recurrent self-evolving fuzzy neural network with local feedbacks and its application to dynamic system processing. Fuzzy Sets Syst. 2010, 161, 2552-2568. [CrossRef]

63. Lin, T.C.; Kuo, C.H.; Balas, V.E. Real-time fuzzy system identification using uncertainty bounds. Neurocomputing 2014, 125, 195-216. [CrossRef]

64. Pedrycz, W.; Izakian, H. Cluster-centric fuzzy modeling. IEEE Trans. Fuzzy Syst. 2014, 22, 1585-1597. [CrossRef]

65. Krishnapuram, R.; Keller, J.M. A possibilistic approach to clustering. IEEE Trans. Fuzzy Syst. 1993, 1, 98-110. [CrossRef] 